\title{
Idiopathic Pulmonary Fibrosis: An Update on Pathogenesis
}

\author{
Qianru Meit, Zhe Liü ${ }^{\dagger}$ He Zuo, Zhenhua Yang* and Jing Qu* \\ School of Basic Medicine, Tongji Medical College, Huazhong University of Science and Technology, Wuhan, China
}

Idiopathic pulmonary fibrosis (IPF) is a progressive, lethal fibrotic lung disease that occurs primarily in middle-aged and elderly adults. It is a major cause of morbidity and mortality. With an increase in life expectancy, the economic burden of IPF is expected to continuously rise in the near future. Although the exact pathophysiological mechanisms underlying IPF remain not known. Significant progress has been made in our understanding of the pathogenesis of this devastating disease in last decade. The current paradigm assumes that IPF results from sustained or repetitive lung epithelial injury and subsequent activation of fibroblasts and myofibroblast differentiation. Persistent myofibroblast phenotype contributes to excessive deposition of the extracellular matrix

\section{OPEN ACCESS}

Edited by:

Jian Fu,

University of Kentucky, United States

Reviewed by:

Richart Harper,

UC Davis Health, United States

Mohamed Ghonim,

St. Jude Children's Research Hospital, United States

*Correspondence: Zhenhua Yang

zhenhua@hust.edu.cn

Jing $Q u$

jingqu@hust.edu.cn

${ }^{\dagger}$ These authors have contributed equally to this work

Specialty section: This article was submitted to Respiratory Pharmacology, a section of the journal

Frontiers in Pharmacology

Received: 18 October 2021 Accepted: 29 December 2021

Published: 19 January 2022

Citation:

Mei Q, Liu Z, Zuo H, Yang Z and Qu J (2022) Idiopathic Pulmonary Fibrosis: An Update on Pathogenesis. Front. Pharmacol. 12:797292. doi: 10.3389/fphar.2021.797292 (ECM) and aberrant lung repair, leading to tissue scar formation, distortion of the alveolar structure, and irreversible loss of lung function. Treatments of patients with IPF by pirfenidone and nintedanib have shown significant reduction of lung function decline and slowing of disease progression in patients with IPF. However, these drugs do not cure the disease. In this review, we discuss recent advances on the pathogenesis of IPF and highlight the development of novel therapeutic strategies against the disease.

Keywords: idiopathic pulmonary fibrosis, pathogenesis, alveolar epithelial cells, fibroblasts, extracellular matrix

\section{INTRODUCTION}

Idiopathic pulmonary fibrosis (IPF) is a chronic and progressive interstitial lung disease of unknown etiology and with a poor prognosis. IPF primarily occurs in middle-aged and elderly adults. In the United States, median age of newly diagnosed patients is 62 years, and $54 \%$ of them are male (Mortimer et al., 2020). The epidemiological survey of IPF shows that the global incidence and prevalence of IPF are in the range of 0.09 and 1.30 per 10,000 people and increasing year by year. Compared with other countries studied, the United States, South Korea and Canada have the highest incidence (Schafer et al., 2020; Maher et al., 2021a). Histopathological characteristics of IPF include excessive deposition of the extracellular matrix (ECM), leading to distortion of normal lung architecture and irreversible loss of lung function (Glass et al., 2020). IPF is clinically manifested by progressive dyspnea and a significant decrease in lung compliance (Schafer et al., 2020). In the past decade, significant progress has been made on our understanding of the mechanisms underlying this disease. The development of IPF is thought to be associated with both genetic and environmental factors. It is proposed that repetitive micro-injuries to alveolar epithelial cells trigger abnormal epithelial-fibroblast communication, which eventually results in abnormal ECM accumulation and pathological lung remodeling (Heukels et al., 2019; Martinez et al., 2017; Richeldi et al., 2017).

There is a growing portfolio of treatment options for IPF. Two drugs, nintedanib and pirfenidone, have been approved for treatment of patients with IPF. Nintedanib is a tyrosine kinase inhibitor, while pirfenidone is an oral pyridine that has anti-inflammatory, antioxidant, and anti-fibrotic effects. The two drugs have demonstrated reduction of lung function decline and slowing of disease 
progression, but they were also associated with some side effects and tolerability issues (Liu et al., 2017). Lung transplantation is the fundamental treatment for IPF. The average survival time of post-transplantation is 4-5 years. However, due to the restricted supply of donor organs and the limitation of chronic allograft rejection, only a few patients can receive this intervention (Kumar et al., 2018). Currently, IPF management is still aim to ameliorate symptoms, improve health status and preserve lung function (Glassberg, 2019). A better understanding of the pathogenesis of IPF will benefit the development of more efficient and safer therapies against IPF. This review will summarize recent advances in the pathogenesis of IPF (Figure 1) and highlight promising novel therapeutic strategies against the devastating fibrotic lung disease.

\section{RISK FACTORS}

\section{Genetic}

Genetic factors play an important role in the development of IPF (Figure 1). Genetic susceptibility of IPF includes single nucleotide polymorphisms (SNPs) and the resultant changes in gene expression. Familial interstitial pneumonia (FIP) is an autosomal dominant genetic disease with variable penetrance in which rare genetic variants have been identified (Kropski et al, 2015; Lorenzo-Salazar et al., 2019). These genetic variations involve the maintenance of telomere length (telomerase reverse transcriptase-TERT, telomerase RNA component-TERC, poly (A) -specific ribonuclease-PARN and regulator of telomere elongation helicase-RTEL) (Barros et al., 2019) and epithelial barrier function (desmoplakin-DSP, dipeptidyl peptidase 9-DPP9, AKAP13, CTNNA) (Allen et al., 2017; Fingerlin et al., 2013). Mutations in Toll-interacting protein (TOLLIP) (encoding an inhibitor of transforming growth factor- $\beta$ (TGF- $\beta$ ) pathway and key regulator of Toll-like receptor-mediated innate immune responses) are associated with decreased expression of TLR mRNA and increased susceptibility to lung infections (Barros et al., 2019).

The genome-wide association studies (GWAS) found that a SNP (rs35705950) in the promoter region of mucin 5B (MUC5B) greatly increases the risk of IPF (Moore et al., 2019). MUC5B contributes to airway mucus production and plays an important role in innate immunity of lungs. Overexpression of MUC5B is related to impaired mucociliary clearance (MCC) and the degree and duration of fibrosis (Hancock et al., 2018; Zhang Q et al., 2019). The rs35705950 minor allele mutation can lead to overexpression of mucin 5B in small airway epithelial cells, and DNA methylation is closely related to genetic susceptibility of MUC5B (Zhang Q et al., 2019). In addition, a study identified a positive feedback bistable ERN2-XBP1S pathway upregulated MUC5B mRNAs in IPF and further regulated mucus secretion, providing an unfolded protein response (UPR)-dependent mechanism with rs35705950 variant (Chen G et al., 2019).

\section{Environmental}

Environmental exposure and genetic predisposition may have a synergistic effect in the development of IPF (Figure 1). In both sporadic and familial pulmonary fibrosis, environmental exposures to lung epithelium can increase the risk of IPF. Of them, smoking and metal dust are the strongest risk factors (Kc et al., 2018; Pardo and Selman, 2020). Cigarette smoke can cause a variety of cellular changes through epigenetic mechanisms. It also induces miRNA imbalance and ER stress, promoting spontaneous lung injury and differentiation from fibroblast to myofibroblast (Mascaux et al., 2009; Song et al., 2019). Pollutants and ultrafine particles in cigarette smoke contain carbon black (CB) and cadmium (Cd). The content of Cd and CB in IPF lung tissue increased significantly and was directly proportional to the amounts of citrullinated vimentin (Cit-Vim). Under activation of Akt1 and peptidylarginine deiminase 2 (PAD2), Cd/CB can induce Vim citrullination and Cit-Vim secretion, which in turn triggers fibroblasts to infiltrate lung microspheres, promotes increased expression of collagen and $\alpha$-smooth muscle actin ( $\alpha$-SMA), and induces lung fibrosis (Li et al., 2021).

Microorganisms (viruses, fungi and bacteria) play a potential role in the pathogenesis of IPF (Lipinski et al., 2020). Compared with normal people, IPF patients have an imbalance in the composition of the lung microbiota, which can serve as a persistent stimuli for repetitive alveolar injury (Molyneaux et al., 2017). The inflammatory and fibrotic mediators and immune disorders in the lungs of IPF patients are related to bacterial load. In animal models of pulmonary fibrosis, pulmonary dysbiosis precedes the peak of lung injury and persists throughout the period of fibrosis. After adjusting the relevant clinical and physiological variables, lung bacterial burden can predict disease progression of IPF patients (O'Dwyer et al., 2019). In addition, Epstein-Barr virus (EBV), cytomegalovirus (CMV) and human herpes virus are detected in alveolar epithelial cells of patients with IPF, suggesting a link between viral infection and increased risk of IPF. Although the mechanisms by which viral infection is associated with IPF remains unclear, studies suggest that it may be related to activation of epithelialmesenchymal transition, promotion of TGF- $\beta$ expression, and induction of epigenetic reprogramming ( $\mathrm{Li}$ et al., 2018; Sides et al., 2011). Interestingly, IPF patients expressing MUC5B risk alleles have a significantly lower bacterial burden compared with the patients who do not bear the risk allele (Molyneaux et al., 2014). NEDD4-2 modulates epithelial $\mathrm{Na}^{+}$channel (ENaC) through ubiquitination, which is essential for proper mucociliary clearance of inhaled irritants and pathogens. Recent study has shown that expression of NEDD4-2 is reduced in IPF lung tissue. NEDD4-2 promotes fibrosis remodeling through regulating the expression of proSP-C, Smad $2 / 3$ and TGF- $\beta$ signaling pathway (Duerr et al., 2020).

\section{Aging}

Aging is a pathological feature of both human IPF and experimental lung fibrosis in animals. The major characteristics of aging lungs include telomere mutations, epigenetic changes, loss of protein homeostasis, mitochondrial dysfunction, and cellular senescence (Figure 1). Telomere 
mutations often result in abnormal DNA repair and genome instability, which serves as a trigger for cell senescence (LopezOtin et al., 2013; Barros et al., 2019). In addition to DNA damage, telomere shortening or damage may also promote fibrosis by impairing tissue repair function, activating p53, reducing mitochondrial biosynthesis, and triggering cellular senescence pathways (Sui et al., 2016; Pineiro-Hermida et al., 2020). There is evidence that in IPF, most of the changes related to aging, including shortening of telomeres which mainly occurs in Alveolar epithelial type II cells (AT2) (Selman et al., 2019). F-box and WD repeat domain-containing protein 7 (FBW7) is identified as a driver of pulmonary premature senescence and fibrosis. It is an E3 ubiquitin ligase that facilitates telomere protective protein 1 (TPP1) multisite polyubiquitination and accelerates degradation through binding to TPP1, thereby triggering telomere uncapping, cause cell senescence and tissue fibrosis (Wang L et al., 2020). Studies have shown that expression of core senescence-related markers is significantly elevated in IPF AT2 cells. These markers include CDKN1A/p21, CDKN2A/p16, TP53, MDM2, CCND1 (Barnes et al., 2019; Liu B et al., 2019). In addition, aging may cause dysfunction of stem/progenitor cell renewal, rendering alveolar epithelial cells incapable of repairing and regenerating injured lungs. Aging epithelial cells can produce a variety of pro-inflammatory and pro-fibrotic mediators, such as Interleukin 6 (IL-6), IL- 1 and TGF- $\beta$, which are part of the senescence-associated secretory phenotype (SASP) (Merkt et al., 2020). In contrast, aging fibroblasts have stronger anti-apoptotic ability to resist environmental stress and can increase extracellular matrix components (Mora et al., 2017; Moore et al., 2019). Metabolic changes, such as glycolytic reprogramming, also play an important role in the pathogenesis of pulmonary fibrosis. Human metabolomics studies have shown that IPF lung tissues displayed increased glycolysis compared with healthy controls (Zhao et al., 2017). Specifically, aging fibroblasts increase glucose utilization and increase resistance to apoptosis (Cho et al., 2017; Selvarajah et al., 2019; Cho and Stout-Delgado, 2020). Studies have suggested that plasminogen activator inhibitor 1 (PAI-1) can protect (myo) fibroblasts from apoptosis in old mice. PAI- 1 is the effector molecule of TGF- $\beta$, which can induce senescence by inducing p21 (Huang et al., 2015). Aged mice develop nonresolving pulmonary fibrosis following lung injury. Intriguingly, p53 signaling is abnormally activated in aging AT2, and silencing the expression of p53 can inhibit the development of progressive fibrosis (Borok et al., 2020; Yao et al., 2020). Changfu $Y$ et al. determined that senescence rather than AT2 cell depletion is the key link in promoting progressive fibrosis, so genetic intervention for p53 activation and senescence will become a therapeutic target for pulmonary fibrosis in the future (Yao et al., 2020). These findings suggest that targeting aged cells may be effective for the treatment of fibrotic lung disease.

\section{Epigenetic Reprogramming}

Increasing evidence demonstrated that under the influence of environmental factors and aging, epigenetic changes play an important role in IPF (Kadel et al., 2019; Yamada, 2020; Yang and Schwartz, 2015). Epigenetic modifications include DNA methylation, histone modifications, and changes in the expression of non-coding RNA (especially microRNA) (Chen et al., 2017). When individuals are exposed to environmental stresses, such as smoke and dust, air pollution can cause epigenetic changes. It has been shown that silica exposure increases expression of DNA methyltransferase 1 (DNMT1) in patients with IPF, leading to the accumulation of collagen and lung fibrosis (Zhang $\mathrm{N}$ et al., 2019).

Genome-wide methylation analysis has shown that there are 2130 differentially methylated regions (DMR) in IPF lungs compared with healthy lungs (Yang et al., 2014). Methylation in these DMRs may regulate expression of multiple target genes and miRNAs involved in the development of IPF (Luo et al., 2020). Changes in DNA methylation correspond to altered mRNA expression of a variety of genes, some of which, such as apoptosis regulation and biosynthesis processes, have known roles in IPF (Cisneros et al., 2012; Rabinovich et al., 2012; Sanders et al., 2012). Regulation of DNA methylation has been demonstrated as a key pathogenetic pathway in TGF- $\beta$ induced lung fibrosis, through reduction of prostaglandin E2 (PGE2) and stimulation of epithelial-mesenchymal transition (Hu et al., 2010; Huan et al., 2015). Li et al. confirmed that MBD2 is highly expressed in macrophages in fibrotic lung. MBD2 is a member of the methyl-CpG-binding domain (MBD) proteins family. It directly binds to methylated $\mathrm{CpG}$ DNA to regulate $\mathrm{PI} 3 \mathrm{~K} /$ Akt signaling, thereby enhancing macrophage M2 program and promoting TGF- $\beta$ signaling (Wang et al., 2021). In addition, HMG AT-hook 2 protein (HMGA2), a member of high-mobility group (HMG) proteins family, can regulate the transcription of its target genes by changing the chromatin structure at the promoter and/or enhancers, which can mediate transformation TGF- $\beta 1$ signaling. Recent studies have found that inhibiting HMGA2FACT-ATM-pH2A.X axis of human lung fibroblasts in vitro could reduce fibrotic hallmarks (Dobersch et al., 2021).

Studies of histone modifications of IPF lungs found that when treated with histone modification-related drugs (TSA, SpA, etc.), the level of surfactant protein $\mathrm{C}(\mathrm{Sp}-\mathrm{C})$, the activation and proliferation of fibroblasts are all significantly affected. Additionally, histone modifications can also affect the antiapoptotic ability of fibroblasts by inhibiting anti-fibrotic genes such as FAS and caveolin 1 (Cav-1) (Bartczak et al., 2020). Ligresti,G et al. identified that histone methyltransferase G9a/ chromobox homolog 5 (CBX5)/methylated lysine 9 residue on histone 3 (H3K9me) were key regulators of fibroblast activation, and determined that by participating in the CBX5/G9a pathway, TGF $\beta$ and increased matrix stiffness effectively inhibited PGC1 $\alpha$ expression in lung fibroblasts (Ligresti et al., 2019).

miRNA microarray analysis showed that expression of miR-21 and miR-199a-5p was increased in IPF lungs, while expression of miR-31, let-7 and miR-200 was decreased (Yang et al., 2015). Among them, miR-21 can induce epithelial-mesenchymal transition (EMT) by inhibiting Smad7 and promote TGF- $\beta$ induced fibrosis (Liu et al., 2010), while Let7 may participate in fibrotic process by targeting HMGA2 (Chirshev et al., 2019). The miR-200 family promote AT2s to restore its ability to transdifferentiate into Alveolar epithelial type I cells (AT1) 
(Moimas et al., 2019). The presence of miR-145 can activate TGF$\beta$ to induce fibrosis, and it can also induce expression of $\alpha$-smooth muscle actin ( $\alpha$-SMA), which is a hallmark of fibroblast to myofibroblast differentiation (Yang et al., 2013). MiR-424 targets Smurf2 (TGF- $\beta$ pathway inhibitor) to promote fibroblast differentiation and promote TGF- $\beta$ secretion (Xiao et al., 2015). MiR-301a can regulate fibroblast activation induced by TGF- $\beta$ and IL-6 (Wang J et al., 2020). miR-29 is a main negative regulator of ECM production. Further studies have found that IPF ECM inhibited miR-29 expression upstream at the transcriptional level, and suppressed Dicer1 downstream at the processing steps to maintain the fibrosis progression (Herrera et al., 2018).

\section{CELLS AND REGULATORS}

\section{Epithelial Cells Damage}

Currently, the prominent initiation of IPF is widely considered to be repeated lung epithelial cell damage and repair dysfunction. Under normal circumstances, the damage of alveolar epithelial cells will lead to recruitment of inflammatory cells, fibrosis and matrix deposition in order to repair the damaged cells. This stage is temporary and then normal pulmonary homeostasis will be restored through activation of apoptotic pathways and phagocytosis of macrophages during the injury repair stage (Desmouliere et al., 1995). However, in IPF lungs, mutations of lung epithelial restriction genes (SFTPC, SFTPA2 and ABCA3) and abnormal expression of genes such as MUC5B cause lung epithelial mucosal barrier dysfunction (Hancock et al., 2018). Repeated stimulation of microorganisms, smoking, gastroesophageal reflux and other factors destroys the integrity of the lung epithelium. In addition, inflammation, excessive production of reactive oxygen species (ROS) and endoplasmic reticulum stress (ERS) in IPF lungs lead to repetitive damage to epithelial cells (Ornatowski et al., 2020).

In the past decades, there has been numerous works to determine the central role of stem cells in epithelial repair, including AT2s and its subsets, basal cells, bronchoalveolar alveolar stem cells (BASC) (Frank et al., 2016; Hewlett et al., 2018). Studies have identified a subset of fibroblasts expressing $\mathrm{PDGFRa}^{+}$or $\mathrm{Lgr}^{+}$can participate in alveolar homeostasis by stimulating Wnt signaling (Axin2+) located in the alveolar compartment. These subset of fibroblasts are involved in promotion of alveolar growth and maturation, and preferentially differentiate into myofibroblasts after lung epithelial injury (Lee et al., 2017; Zepp et al., 2017).

\section{Lung Stem Cells Dysfunction and Exhaustion}

In IPF, genetic and environmental factors may cause damage to AT1s, while dysfunction of AT2s makes it difficult to repair the damaged AT1s. AT2s, serve as the predominant epithelial progenitor in alveoli, play an important role in maintaining lung homeostasis (Parimon et al., 2020). Abnormal function of alveolar epithelial cells is associated with activation of signal pathways such as Wnt/ $\beta$-catenin and Sonic Hedgehog (Stewart et al., 2003; Nabhan et al., 2018; Reyfman et al., 2019). Recent study identified a rare subset of mature AT2 cells with stem cell propertie marked by continuous expression of the Wnt target gene Axin2. Canonical Wnt signaling pathway blocks reprogramming of alveolar stem cells into AT1 cells. When injury occurs in epithelial cells, Wnt signaling pathway is activated and participates in " ancillary" AT2 stem cell progenitor cell activity (Nabhan et al., 2018). Wnt-reactive alveolar epithelial progenitor cells (AEP) in AT2 are a stable lineage during alveolar homeostasis, but rapidly expand to regenerate most of the alveolar epithelium after acute lung injury, showing stronger "stemness". AEPs have a unique transcriptome, epigenome and functional phenotype, and specifically respond to Wnt and Fgf signaling (Zacharias et al., 2018). It has been believed that repetitive micro-injuries are a potential cause of AT2 depletion. However, the reduction of AT2 number in IPF lung supports the idea of stem cell exhaustion. In addition, aging, ERS and mitochondrial dysfunction play an important role in AT2 depletion and impaired self-renewal (Kropski and Blackwell, 2018; Borok et al., 2020; Parimon et al., 2020). Loss of Cdc42 in AT2s results in impaired differentiation, exposing alveolar cells to sustained elevated mechanical tension which activates a TGF- $\beta$ signaling loop in AT2 cells in a spatially regulated manner, thereby promoting lung fibrosis progression from periphery to center (Wu et al., 2020).

\section{Fibroblasts and Myofibroblasts}

In IPF, pro-fibrotic mediators secreted by activated fibroblasts continue to act on fibroblasts to form a positive feedback, which leads to production of ECM and myofibroblast differentiation (Wipff et al., 2007). TGF- $\beta$ is considered to be the primary factor that promotes fibroblast differentiation into myofibroblasts (Huang et al., 2020). Myofibroblasts secrete more ECM than fibroblasts. They are the main collagen-producing cells in the lung and are characterized by expression of contractile protein $\alpha$ SMA and fibroblast activation protein (FAP) (Tsukui et al., 2020). FAP is a membrane-spanning protein that is essential for collagen remodeling. As FAP exhibits a low expression state in most healthy cells, it can be used as a molecular marker to exploit for specifically target drugs to fibroblasts that cause fibrosis (Hettiarachchi et al., 2020).

In the normal wound healing process, unwanted fibroblasts are eliminated by activating the apoptotic pathway. The elimination mechanism of fibroblasts limits the ongoing matrix deposition and fibrosis (Desmouliere et al., 1995). In IPF, myofibroblasts were found to resist FAS ligand-induced apoptosis and have stronger proliferation ability when grown on polymerized collagen (Xia et al., 2008; Nho et al., 2011). FasL, Tumor necrosis factor (TNF)-related apoptosis-inducing ligand (TRAIL) and Cav-1 protein expression in these cells decreased, while AKT activity increased (Hohmann et al., 2019). In addition, myofibroblast contraction is irreversible, which contribute to regulate the remodeling of collagen, trigger the spatial structural reorganization of collagen fibrils, increase their mechanical stress, and stiffen the ECM (Zhou et al., 2020). Periostin is highly expressed in IPF lungs. Further studies have 
found that in lung fibroblasts, periostin/integrin $\alpha \mathrm{V} \beta 3$ can promote expression of cell cycle-related molecules, including cyclins, cyclin-dependent kinases (CDKs) and E2F families, and transcription factors (such as B-MYB and FOXM1), which play a vital role in the proliferation of lung fibroblasts (Yoshihara et al., 2020).

\section{Basal Cells}

An important feature of epithelial cell remodeling in IPF is the expansion of distal basal cells, which can serve as stem/progenitor cells of the pseudostratified epithelium of the lung. In the cellular area of IPF, secretory sensitized basal cells (SPB) are enriched, and the formation and secretion function of its subpopulations are regulated by Notch signal. Specifically, NOTCH2 restricts the differentiation of basal cells, while NOTCH3 can inhibit secretory differentiation (Carraro et al., 2020). In addition, RNA-seq analysis for IPF indicates that expression of LncRNA MEG3 in basal cells increased. MEG3 plays a role in abnormal epithelial cell differentiation in IPF and regulates epithelial cell migration related genes including TP63, STAT3, KRT14, YAP1 and AXL, which together contribute to the restructuring of IPF (Gokey et al., 2018). Milena S et al. confirmed that MMP9 expressed by airway base cells (ABC) in IPF was significantly increased and regulated by TGF- $\beta$ pathway. When targeting MMP9, the anti-fibrotic effect is related to the reduction of TGF- $\beta$ activation in a subgroup of IPF patients, which reveals an association with expression of type 1 IFN in ABC-like cells (Espindola et al., 2021).

\section{Growth Factors}

There is overwhelming evidence in support of a key role of TGF- $\beta$ in the pathogenesis of IPF (Huang et al., 2020). TGF- $\beta$ promotes epithelial-mesenchymal transition, epithelial cell migration, fibroblast proliferation, activation, and differentiation into myofibroblasts (Figure 1). TGF- $\beta$ can also increase the production of other fibrotic mediators and pro-angiogenic mediators (Grimminger et al., 2015; Song et al., 2020). TGF- $\beta$ is synthesized as a latent complex by binding to the latencyrelated peptide (LAP), which covalently binds to the ECM protein (Biernacka et al., 2011). Latent TGF- $\beta$ can be activated by a range of factors, including $\alpha v \beta 6$ integrin (John et al., 2020). In IPF, expression of $\alpha v \beta 6$ in alveolar epithelial cells is increased, which binds to LAP to induce TGF- $\beta$ activation (Jenkins et al., 2006). Once activated, TGF- $\beta$ binds to its receptors and stimulates phosphorylation of transcription factor Smad3. PhosphoSmad3 interacts with Smad4 to form a complex which translocates into the nucleus to induce expression of target genes, including profibrotic genes such as a-SMA, CTGF and ECM major collagen 1A1 (COL1A1) (Biernacka et al., 2011; Massague, 2012). Interestingly, the expression of negativeregulating factor tripartite motif 33 (TRIM33) of TGF- $\beta$ / SMAD in IPF increased. TRIM33 is an E3 ubiquitin ligase, which can promote SMAD4 ubiquitination and induce SMAD4 to export from the nucleus, thereby inhibiting transcriptional activity of SMADs. However, the combination of TRIM33 and small heat shock protein (HSPBS) weakened its inhibitory activity. The upregulation of TRIM33 may be regarded as a failed attempt to prevent the progression of fibrosis in IPF and lung fibrosis models (Boutanquoi et al., 2020).

CTGF, also known as cellular communication network factor 2 (CCN2), is an important mediator of organ fibrosis in human body (Falke et al., 2020; Wang et al., 2019). It is considered to be a predictor of pulmonary fibrosis disease and a potential target for anti-fibrosis therapy (Leask, 2011). CTGF is secreted and activated under stimulation of TGF- $\beta$. CTGF mediates lung matrix deposition and fibroblast differentiation by activating downstream MAP kinase pathway (Duncan et al., 1999; Inui et al., 2021). In addition, CXCL12 can also induce the expression of CTGF in human lung fibroblasts by activating the MEKK1/ JNK signaling pathway (Lin et al., 2018). Studies have found that gene promoter of CTGF contains numerous transcription factor binding sites such as NF- $\kappa B$, signal transducer and activator of transcription (STAT), activator protein-1 (AP-1) and SMAD (Lin et al., 2018), indicating these factors may affect IPF through CTGF.

PDGF is widely expressed in macrophages, platelets, endothelial cells and fibroblasts (Hewlett et al., 2018). Highly expressed PDGF can be detected in BALF of IPF patients and bleomycin-induced IPF model mice (Phan et al., 2021). The abnormal expression and signal transduction of PDGF ligands and receptors have been confirmed to be closely related to IPF. In IPF, TGF- $\beta$ signaling promotes expression of PDGF-B through regulatory T cells (Tregs), thereby stimulating PDGF-B-mediated fibroblast proliferation and migration (Kanaan and Strange, 2017; Kishi et al., 2018).

Insulin-like growth factor (IGF1) is a key molecule that regulates cellular senescence (Duran-Ortiz et al., 2021). As mentioned above, senescence has been identified as an important reason for the weakened repair function of AT2s in IPF. Under pathological conditions, ATs release IGF1, which activates the surface of adjacent normal ATs. IGF receptor (IGFR1 ), and further activate the PI3K/AKT signaling pathway, and participate in ATs senescence and IPF by releasing CTGF, TGF$\beta 1$ and MMP9 (Sun et al., 2021).

\section{MOLECULAR MECHANISMS}

\section{Extracellular Matrix Deposition}

The massive deposition of extracellular matrix in IPF is mainly involved in changes in two families of proteins: MMPs and tissue inhibitors of metalloproteinases (TIMPs) (Figure 1). Studies have found that expression levels and localization of MMP and TIMP in IPF lungs undergo substantial changes. The levels of MMP1, MMP2, MMP9 and the four TIMPs are up-regulated. Among them, MMP1 is more common in alveolar macrophages and epithelial cells, while TIMP is highly expressed by myofibroblasts in IPF fibroblastic foci (Betensley et al., 2016). The extracellular matrix of IPF can also change transcriptional profile of lung fibroblasts and affect the translation of ECM proteins, such as COL1A1, COL1A2, COL3A1, COL5A2, COL4A2, MMP2, MMP3, MMP10 and TIMP2 (Zolak and de Andrade, 2012). Together, these findings suggest that there is a positive feedback pathway between fibroblasts and abnormal ECM, in which the 
fibrotic extracellular matrix is both the cause and the result of fibroblast activation (Guiot et al., 2017).

\section{Matrix Stiffness and Scaffolding}

Matrix stiffening is a prominent feature of lung fibrosis. Compared with healthy lung scaffolds, IPF scaffolds increase tissue stiffness, density, ultimate force, and differential expressions of matrisome proteins (Figure 1). The collagen, proteoglycan and ECM glycoprotein in the IPF scaffold increased, but specific basement membrane (BM) proteins (such as laminins and collagen IV) were decreased, while nidogen-2 was increased, accompanied by periostin and proteoglycans production were increased (Elowsson Rendin et al., 2019). The increased stiffness of ECM tissue is a result of dysregulated collagen cross-linking, which is related to posttranslational modification of collagen involved in lysyl oxidaselike (LOXL) 2 and LOXL3 (Jones et al., 2018). ECM stiffness participates in the pathogenesis of IPF. Accumulating evidence indicates that mechanical interactions between fibroblasts and the stiffened ECM provide a feedforward mechanism that sustains and/or perpetuates pulmonary fibrosis (Zhou et al., 2013).

In previous study, we demonstrated that matrix stiffness regulates the ability of fibrotic lung myofibroblasts to invade the $\mathrm{BM}$, by increasing a6-expression, mediating MMP-2dependent pericellular proteolysis of BM collagen IV. Genetic ablation of a6 in collagen-expressing mesenchymal cells or pharmacological blockade of matrix stiffness-regulated a6expression protects mice against bleomycin injury-induced experimental lung fibrosis. Studies found that a mechanotransduction pathway involving Rho/Rho kinase (Rho/ROCK), actin cytoskeletal remodeling, and a mechanosensitive transcription factor, megakaryoblastic leukemia 1 (MKL1), that coordinately regulate myofibroblast differentiation, and pharmacologic disruption of this pathway with the ROCK inhibitor fasudil induced myofibroblast apoptosis through a mechanism involving downregulation of BCL-2 and activation of the intrinsic mitochondrial apoptotic pathway (Zhou et al., 2013). Recently, we have shown that mouse double minute 4 homolog (MDM4) is a matrix stiffnessregulated endogenous inhibitor of p53. MDM4 is highly expressed in the fibrotic lesions of human IPF and experimental pulmonary fibrosis in aged mice. Our studies provides evidence that mechanosensitive MDM4 is a molecular target with promising therapeutic potential against persistent lung fibrosis associated with aging (Qu et al., 2021). Moreover, ECM stiffness is sensitive to exogenous TGF- $\beta$ stimulation through inhibiting the interaction of inner nuclear membrane protein LEM domain-containing protein 3 (LEMD3) and SMAD2/3. LEMD3 is physically connected to the actin cytoskeleton of cells and inhibits TGF- $\beta$ signaling (Chambers et al., 2018). At the metabolic level, increased matrix stiffness impairs the synthesis of anti-fibrotic lipid mediator PGE2 and reduces expression of rate-limiting prostaglandin biosynthetic enzyme cyclooxygenase 2 (COX-2) and prostaglandin E synthesis (PTGES) through p38/MAPK signaling pathway (Berhan et al., 2020). Genome-wide association studies (GWASs) have identified DSP (desmoplakin) gene, a type of intercellular junction responsible for maintaining the structural integrity and mechanical stability of the epithelium, as a significant locus associated with IPF (Fingerlin et al., 2013; Mathai et al., 2016; Allen et al., 2017; Tasha E). Our studies demonstrated that matrix stiffness regulates DSP gene expression by an epigenetic mechanism involving alteration of DNA methylation in the DSP promoter. Targeted DNA methylation by CRISPR (clustered regularly interspaced short palindrom2076295ic repeats)/dCas9 (deactivated CRISPR-associated protein-9 nuclease)-mediated epigenome editing effectively reverses stiff matrix-induced DSP overexpression (Qu et al., 2018). We speculate that aberrant DSP expression in IPF may not only represent a robust and persistent epithelial response to chronic/repetitive lung injury but also actively participate in aberrant lung repair and/or the restoration of lung epithelial function (Qu et al., 2018). In addition, studies have identified that rs2076295 (an intron variant in DSP gene) was related to IPF susceptibility and directly regulated DSP expression in human airway epithelial cells. Deletion of DSP enhances expression of extracellular matrix-related genes such as matrix metalloproteinases 7 (MMP7) and MMP9 and promotes cell migration (Hao et al., 2020). For IPF patients with DSP alleles and MUC5B alleles, the mortality rate is lower, and anti-fibrosis drugs are more effective in treatment (Doubkova et al., 2021). These studies indicate that targeting mechanosensitive signaling in myofibroblasts may be an effective approach for treatment of fibrotic disorders.

\section{Endoplasmic Reticulum Stress}

Endoplasmic reticulum stress (ERS) occurs when there is an imbalance between cell's demand for protein synthesis and the ability of endoplasmic reticulum to synthesize, process, and package proteins. As ERS occurs, cells activate an UPR, which attempts to restore normal function of the endoplasmic reticulum. When ERS is persisting or severe, it triggers cell apoptosis (Kropski and Blackwell, 2018; Hipp et al., 2019). It has been observed that markers of UPR activation in AT2 in IPF patients are elevated (Kropski and Blackwell, 2018; Baek et al., 2020). ERS may synergize with inflammation and viral infection to induce epithelial cell damage (Chen $T$ et al., 2019). In IPF, UPR stimulates the production of fibrotic mediators, such as TGF- $\beta$, PDGF (platelet-derived growth factor), CXCL12 (CXC chemokine 12), CCL2 (chemokine CC ligand 2) (Wolters et al., 2014; Kropski and Blackwell, 2018). The chaperone protein GRP78 (glucose regulatory protein 78) is the main regulator of ER homeostasis and suppresses UPR by interacting with transmembrane ER stress sensors. It is found that the expression of GRP78 in AT2 cells from old mice and IPF lungs decreased, while GRP78 knocked out will induce ERS, apoptosis and lung inflammation to promote fibrosis (Borok et al., 2020). Otherwise, thioredoxin domain containing 5 (TXNDC5), an ER protein enriched in fibroblasts, is highly up-regulated in fibroblasts from IPF lung/BLM-induced mouse and enhances TGF- $\beta$ signaling by increasing and stabilizing TGFbeta receptor 1 (TGFBR1), while TGF- $\beta$ promotes TXNDC5 expression via ATF6 ER stress pathway, forming a positive feedback loop (Lee et al., 2020). Mutations in the genes encoding surfactant proteins [surfactant protein C (SFTPC) 


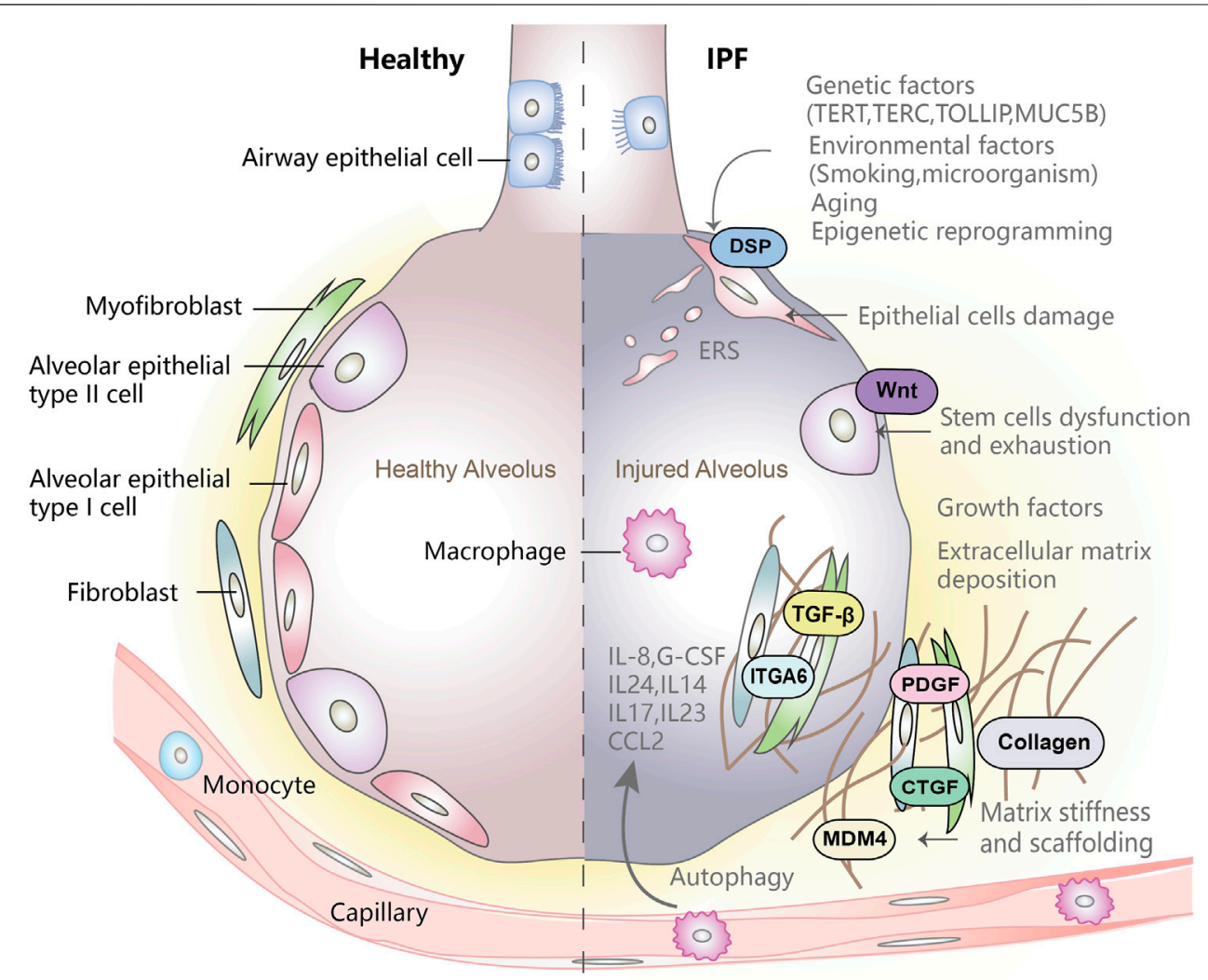

FIGURE 1 |Pathogenesis of idiopathic pulmonary fibrosis. Genetic factors affect the integrity of epithelial cells, environmental factors and aging-related changes will trigger epigenetic reprogramming. The combined action of the three factors will cause epithelial cell damage and trigger the abnormal activation of epithelial cells. Activated epithelial cells secretes a large number of cytokines such as TGF- $\beta$ which consequently promotes fibroblast migration and proliferation, and also promote fibroblasts to differentiate into myofibroblasts. Myofibroblasts secrete large amounts of ECM, leading to ECM deposition. In addition, epithelial cell damage, disfunction and exhaustion of stem cells, abnormal deposition of extracellular matrix and matrix stiffness play a vital role in progression of abnormal lung fibrosis and remodeling of lung structure.

and A2 (SFTPA2)] can lead to abnormal surfactant folding and ERS, and promote epithelial-mesenchymal transition (Mulugeta et al., 2015; Takezaki et al., 2019).

\section{Inflammation and Immunity}

The role of inflammation in the development of IPF remains controversial. In the early stage of alveolar injury, neutrophils are recruited into the injured sites, triggering an immune response by releasing pro-inflammatory cytokines and producing neutrophil elastase $(\mathrm{NE})$ to exacerbate fibrosis (Le Saux and Chapman, 2018). Elevated IL-8 and G-CSF have been found in the bronchoalveolar lavage fluid (BALF) and sputum of IPF patients, suggestive of infiltration and activation of neutrophils (Figure 1). IL-8 promotes the development of fibrosis through elastase-mediated activation of TGF- $\beta$ (Betensley et al., 2016; Guiot et al., 2017; Heukels et al., 2019). IL-24 and IL-4 can synergistically induce M2 program of macrophages, thereby promoting the development of lung fibrosis (Rao et al., 2021). IL17 secreted by Th17 cells can directly promote fibrosis. In acute exacerbation of pulmonary fibrosis, the levels of IL17 and IL23 are increased, and treatment with interleukin-23 antibody can significantly attenuate airway inflammation and fibrosis and reduce IL17 level, suggesting IL23 is essential for the development of acute exacerbation of pulmonary fibrosis (Senoo et al., 2021). Monocyte and macrophages drive fibrosis through excessive repair responses to alveolar cell injury. Compared with normal lungs, the subpopulation of macrophages that highly express SPP1 and MERTK (SPP1hi) and NTN1 (laminin-like protein netrin-1) increased significantly in IPF lungs. The highly proliferated SPP1hi macrophages upregulate the expression of type 1 collagen and MMP2 and contribute to tissue repair and fibrosis (Morse et al., 2019). It has been reported that macrophage-derived NTN1 drive the development of fibrosis through a mechanism involving remodeled adrenergic nerves and their secretory product noradrenaline and $\alpha_{1}$ adrenoreceptors (Gao et al., 2021). CCL2 and colony stimulating factor (M-CSF/CSF1) derived from monocytes/macrophages may have a direct fibrotic effect (Coward et al., 2010). Furthermore, recent studies have identified that immune cells in lung tissue predict the severity of IPF and participate in the progress of this disease, 
TABLE 1 | Drugs used in the treatment of Idiopathic pulmonary fibrosis (IPF).

\begin{tabular}{|c|c|c|}
\hline Drugs & Mechanism of action & References \\
\hline Pirfenidone & Anti-fibrotic drug & Nathan et al. (2019) \\
\hline Nintedanib & Anti-PDGFR, VEGFR, FGFR drug & Flaherty et al. (2019), Makino (2021) \\
\hline Pamrevlumab & Anti-CTGF antibody & Richeldi et al. (2020) \\
\hline GSK3008348 & $\alpha \vee \beta 6$ antagonist & John et al. (2020) \\
\hline sildenafil & phosphodiesterase-5 inhibitor & Kang \& Song, (2021) \\
\hline Co-trimoxazole or doxycycline & Antimicrobial drug & Wilson et al. (2020) \\
\hline Lebrikizumab & Anti-IL13 & Maher et al. (2021b) \\
\hline Carlumab & Anti-CCL2 & Raghu et al. (2015) \\
\hline Simtuzumab & Anti-LOX antibody & Raghu et al. (2017) \\
\hline
\end{tabular}

which can be used as a reference indicator (Wang $\mathrm{Z}$ et al., 2020).

\section{Autophagy}

Autophagic pathways (including macroautophagy and mitophagy) in IPF lung epithelial cells and fibroblasts are reduced, aggravating inflammation and fibrosis (Racanelli et al., 2018). Autophagy is involved in the regulation of ECM formation (Lin and Xu, 2020). Studies have shown that increasing autophagy clearance of type 1 collagen in lung fibroblasts can reduce invasiveness of IPF fibroblasts (Surolia et al., 2019). In addition, expression of the autophagy marker LC3B has been found to be significantly reduced in IPF lung fibroblasts (Ghavami et al., 2018). Specifically, the Akt signal pathway directly acts on FoxO3a to reduce its expression, further inhibiting production of autophagy marker LC3B on the collagen matrix, leading to excessive collagen accumulation (Im et al., 2015).

\section{TREATMENTS}

Recent research on pathogenesis of IPF has promoted notable advances in pharmacotherapeutic treatment. There are currently two recommended antifibrotic drugs, nintedanib and pirfenidone, have been shown to delay the progression of pulmonary fibrosis and reduce mortality, but there is still no cure for IPF (Cerri et al., 2019; Somogyi et al., 2019). Therefore, new treatment methods and drug targets are needed. Here we summarize some important novel drugs that have been tested in phase II-III trails (Table 1). The potential molecular targets of the drugs are also discussed. In addition, strategies of nonpharmacological treatment such as symptomatic support therapy, lung transplantation, comorbidities and management of acute exacerbation of IPF (AE-IPF) are believed to improve symptom control and quality of life (Caminati et al., 2019).

\section{Pirfenidone}

Pirfenidone (PFD) is a pharmacological compound for IPF treatment (Flaherty et al., 2019). PFD treatment can reduce all-cause mortality and risk of hospitalization, and benefit patients with advanced pulmonary fibrosis (Nathan et al., 2019). The mechanism of PFD treating IPF is currently unclear. PFD can inhibit TGF- $\beta$-mediated fibroblast proliferation and differentiation of fibroblasts into myofibroblasts by attenuating signal transduction induced by TGF- $\beta 1 /$ Smad3 (Molina-Molina et al., 2018). In addition, PFD can also inhibit differentiation of myofibroblasts by regulating PDFG, a fibroblast mitogen receptor, but the specific mechanism is still unclear (Ruwanpura et al., 2020). Studies have found that PFD can resist the loss of E-cadherin, the main intermediary protein of A549 cell epithelial cell transformation induced by TGF- $\beta$, and pulmonary fibrosis in a rat model of silicosis, indicating that PFD can also inhibit epithelial cell transformation (Zhang Y et al., 2019). The oxidative stress process in lung diseases leads to irreversible oxidative modification of protein and DNA and mitochondrial dysfunction. PFD treatment can improve mitochondrial respiration, possibly by detoxifying mitochondrial peroxidase, such as glutathione peroxidase, thus revealing ability to maintain normal mitochondrial function (Plataki et al., 2019). Therefore, PFD's anti-fibrosis effect may function through reducing the formation of reactive oxygen species and oxidative stress.

\section{Nintedanib}

Nintedanib is a triple tyrosine kinase inhibitor with anti-fibrotic effects. In IPF treatment, Nintedanib can reduce the decline of forced vital capacity (FVC) and inhibit progression of pulmonary fibrosis (Flaherty et al., 2019; Makino, 2021). In previous clinical treatments, its safety and tolerability were acceptable. The most common adverse reaction is gastrointestinal infection, manifested as diarrhea and nausea (Bendstrup et al., 2019). Nintedanib can block activation of PDGF receptor, fibroblast growth factor receptor, vascular endothelial growth factor receptor and Src family kinases. Its anti-fibrosis effect is achieved through a variety of mechanisms, including blocking differentiation from fibroblasts into myofibroblasts, inhibiting EMT, inflammation and angiogenesis (Liu F et al., 2019).

\section{Combination Therapies}

As mentioned above, pulmonary fibrosis is a complex pathological progression in which pathogenic factors activate complex fibrotic pathways in various cells (Schafer et al., 2020). Therefore, combined treatment of multiple drugs with different targets and mechanisms involved in IPF is of great significance, but adverse effects and tolerance also need attention. It is currently proven that the combination therapy of pirfenidone and nintedanib has controllable safety and tolerability (Vancheri 
et al., 2018). Although this study has no efficacy evaluation, it still provides a significant research direction for combination therapy of pulmonary fibrosis.

In a recent clinical phase $2 \mathrm{~b}$ trial, patients with advanced IPF and pulmonary hypertension were treated with pirfenidone plus sildenafil for up to 52 weeks. Unfortunately, there was no therapeutic effect. (Behr et al., 2021). Furthermore, the combination therapy of nintedanib and sildenafil only has pronounced effects on IPF patients who have right heart dysfunction (RHD) (Behr et al., 2019). Combination treatment with inhaled $\mathrm{N}$-acetylcysteine and pirfenidone for 48 weeks may lead to a worse prognosis of IPF (Sakamoto et al., 2021). These clinical trials indicate that combination therapies for pulmonary fibrosis still need to be explored for a long time.

\section{Novel Therapies}

Due to adverse effects of currently drugs for IPF and there is no effective cure, IPF research is increasingly focused on developing new molecular targets and treatment options. As mentioned above, CTGF is an important pro-fibrotic growth factor associated with extracellular matrix secretion and abnormal tissue repair (Yanagihara et al., 2021). A recent phase II clinical trial has confirmed that treatment of pamrevlumab, which is a fully human recombinant monoclonal antibody against CTGF, can significantly reduce the decline of FVC and attenuate the progression of IPF. And importantly, it is shown that pamrevlumab has good safety and tolerability which is expected to become a new anti-fibrotic drug (Richeldi et al., 2020). In addition, $\alpha v \beta 6$ integrin is the key molecule for activating TGF- $\beta$. A selective small molecule RGD-mimetic $\alpha v \beta 6$ inhibitor GSK3008348, which can bind to $\alpha v \beta 6$ with high affinity in human IPF lung epithelial cells, induces av $\beta 6$ internalization and degradation, and inhibits activation of downstream TGF- $\beta$. In the bleomycin-induced mouse lung fibrosis model, significantly reduce lung collagen deposition and serum C3M (a marker of IPF disease progression). At present, inhaled GSK3008348 is safe and well tolerated in phase 1 clinical trials, which may be helpful for development of anti-fibrosis drugs in the future (John et al., 2020).

\section{CONCLUSION AND OUTLOOK}

Idiopathic pulmonary fibrosis is an interstitial pulmonary disease with high mortality. It is associated with a large economic and

\section{REFERENCES}

Allen, R. J., Porte, J., Braybrooke, R., Flores, C., Fingerlin, T. E., Oldham, J. M., et al. (2017). Genetic Variants Associated with Susceptibility to Idiopathic Pulmonary Fibrosis in People of European Ancestry: a Genome-wide Association Study. Lancet Respir. Med. 5 (11), 869-880. doi:10.1016/S2213-2600(17)30387-9

Baek, A. R., Hong, J., Song, K. S., Jang, A. S., Kim, D. J., Chin, S. S., et al. (2020). Spermidine Attenuates Bleomycin-Induced Lung Fibrosis by Inducing Autophagy and Inhibiting Endoplasmic Reticulum Stress (ERS)-induced Cell Death in Mice. Exp. Mol. Med. 52 (12), 2034-2045. doi:10.1038/ s12276-020-00545-z healthcare burden. Genetic and epigenetic changes are important factors in the pathogenesis of IPF, although the definite cause of IPF has yet to be clarified. Our understanding of the pathogenesis of IPF have significantly improved in the past decade. In the last few years, the research progress of idiopathic pulmonary fibrosis has highlighted the important role of stem cell dysfunction and extracellular matrix in mediating lung pathological remodeling and promoting the process of fibrosis (Deng et al., 2020; Wu et al., 2020). Unfortunately, IPF has a very small number of treatments and is still not curable. Nintedanib and pirfenidone can slow the progression of the disease. However, adverse reactions limit their use (Spagnolo et al., 2018). A better understanding of the pathogenesis of IPF and the signal pathways will benefit the development of more effective drug therapies. Gene editing technology provides a promising tool for developing novel treatments for human diseases. CRISPR-mediated genome and epigenome editing may prove to be effective means for correction of abnormal gene expression associated with IPF, thus representing an important direction in the future research. In addition, recent dynamic research activities in IPF pathogenesis have led to the foundation of some novel treatment strategies and identification of therapeutic targets. Several targeted drugs have been further synthesized and developed, and currently under clinical trials. Some of these drugs have been confirmed their effectiveness and safe tolerance. They are expected to become new IPF specific drugs to improve progression of IPF and other fibrosis diseases in the near future.

\section{AUTHOR CONTRIBUTIONS}

JQ and ZY guided the scope and research background of the research, and wrote the manuscript. QM wrote the original version of this manuscript. $\mathrm{ZL}$ and $\mathrm{HZ}$ critically revised the manuscript.

\section{FUNDING}

This work was supported by the National Natural Science Foundation of China (Grant No. 81900067, 82170083) and Fundamental Research Funds for the Central Universities to JQ, Fundamental Research Funds for the Central Universities to $\mathrm{ZY}$.

Barnes, P. J., Baker, J., and Donnelly, L. E. (2019). Cellular Senescence as a Mechanism and Target in Chronic Lung Diseases. Am. J. Respir. Crit. Care Med. 200 (5), 556-564. doi:10.1164/rccm.201810-1975TR

Barros, A., Oldham, J., and Noth, I. (2019). Genetics of Idiopathic Pulmonary Fibrosis. Am. J. Med. Sci. 357 (5), 379-383. doi:10.1016/ j.amjms.2019.02.009

Bartczak, K., Białas, A. J., Kotecki, M. J., Górski, P., and Piotrowski, W. J. (2020). More Than a Genetic Code: Epigenetics of Lung Fibrosis. Mol. Diagn. Ther. 24, 665-681. doi:10.1007/s40291-020-00490-7

Behr, J., Kolb, M., Song, J. W., Luppi, F., Schinzel, B., Stowasser, S., et al. (2019). Nintedanib and Sildenafil in Patients with Idiopathic Pulmonary Fibrosis and Right Heart Dysfunction. A Prespecified Subgroup Analysis of a Double- 
Blind Randomized Clinical Trial (INSTAGE). Am. J. Respir. Crit. Care Med. 200 (12), 1505-1512. doi:10.1164/rccm.201903-0488OC

Behr, J., Nathan, S. D., Wuyts, W. A., Mogulkoc Bishop, N., Bouros, D. E., Antoniou, K., et al. (2021). Efficacy and Safety of Sildenafil Added to Pirfenidone in Patients with Advanced Idiopathic Pulmonary Fibrosis and Risk of Pulmonary Hypertension: a Double-Blind, Randomised, PlaceboControlled, Phase 2b Trial. Lancet Respir. Med. 9 (1), 85-95. doi:10.1016/ S2213-2600(20)30356-8

Bendstrup, E., Wuyts, W., Alfaro, T., Chaudhuri, N., Cornelissen, R., Kreuter, M., et al. (2019). Nintedanib in Idiopathic Pulmonary Fibrosis: Practical Management Recommendations for Potential Adverse Events. Respiration 97 (2), 173-184. doi:10.1159/000495046

Berhan, A., Harris, T., Jaffar, J., Jativa, F., Langenbach, S., Lönnstedt, I., et al. (2020). Cellular Microenvironment Stiffness Regulates Eicosanoid Production and Signaling Pathways. Am. J. Respir. Cell Mol Biol 63, 819-830. doi:10.1165/ rcmb.2020-0227OC

Betensley, A., Sharif, R., and Karamichos, D. (2016). A Systematic Review of the Role of Dysfunctional Wound Healing in the Pathogenesis and Treatment of Idiopathic Pulmonary Fibrosis. J. Clin. Med. 6 (1). doi:10.3390/jcm6010002

Biernacka, A., Dobaczewski, M., and Frangogiannis, N. G. (2011). TGF- $\beta$ Signaling in Fibrosis. Growth Factors 29 (5), 196-202. doi:10.3109/08977194.2011.595714

Borok, Z., Horie, M., Flodby, P., Wang, H., Liu, Y., Ganesh, S., et al. (2020). Grp78 Loss in Epithelial Progenitors Reveals an Age-Linked Role for Endoplasmic Reticulum Stress in Pulmonary Fibrosis. Am. J. Respir. Crit. Care Med. 201 (2), 198-211. doi:10.1164/rccm.201902-0451OC

Boutanquoi, P. M., Burgy, O., Beltramo, G., Bellaye, P. S., Dondaine, L., Marcion, G., et al. (2020). TRIM33 Prevents Pulmonary Fibrosis by Impairing TGF-B1 Signalling. Eur. Respir. J. 55 (6). doi:10.1183/13993003.01346-2019

Caminati, A., Lonati, C., Cassandro, R., Elia, D., Pelosi, G., Torre, O., et al. (2019). Comorbidities in Idiopathic Pulmonary Fibrosis: an Underestimated Issue. Eur. Respir. Rev. 28 (153). doi:10.1183/16000617.0044-2019

Carraro, G., Mulay, A., Yao, C., Mizuno, T., Konda, B., Petrov, M., et al. (2020). Single-Cell Reconstruction of Human Basal Cell Diversity in Normal and Idiopathic Pulmonary Fibrosis Lungs. Am. J. Respir. Crit. Care Med. 202, 1540-1550. doi:10.1164/rccm.201904-0792OC

Cerri, S., Monari, M., Guerrieri, A., Donatelli, P., Bassi, I., Garuti, M., et al. (2019). Real-life Comparison of Pirfenidone and Nintedanib in Patients with Idiopathic Pulmonary Fibrosis: A 24-month Assessment. Respir. Med. 159, 105803. doi:10.1016/j.rmed.2019.105803

Chambers, D. M., Moretti, L., Zhang, J. J., Cooper, S. W., Chambers, D. M., Santangelo, P. J., et al. (2018). LEM Domain-Containing Protein 3 Antagonizes TGF $\beta$-SMAD2/3 Signaling in a Stiffness-dependent Manner in Both the Nucleus and Cytosol. J. Biol. Chem. 293 (41), 15867-15886. doi:10.1074/ jbc.RA118.003658

Chen, G., Ribeiro, C. M. P., Sun, L., Okuda, K., Kato, T., Gilmore, R. C., et al. (2019). XBP1S Regulates MUC5B in a Promoter Variant-dependent Pathway in Idiopathic Pulmonary Fibrosis Airway Epithelia. Am. J. Respir. Crit. Care Med. 200 (2), 220-234. doi:10.1164/rccm.201810-1972OC

Chen, T., Qiu, H., Zhao, M. M., Chen, S. S., Wu, Q., Zhou, N. Y., et al. (2019). IL17A Contributes to HSV1 Infection-Induced Acute Lung Injury in a Mouse Model of Pulmonary Fibrosis. J. Cell Mol Med 23 (2), 908-919. doi:10.1111/ jcmm.13992

Chen, Z., Li, S., Subramaniam, S., Shyy, J. Y., and Chien, S. (2017). Epigenetic Regulation: A New Frontier for Biomedical Engineers. Annu. Rev. Biomed. Eng. 19, 195-219. doi:10.1146/annurev-bioeng-071516-044720

Chirshev, E., Oberg, K. C., Ioffe, Y. J., and Unternaehrer, J. J. (2019). Let-7 as Biomarker, Prognostic Indicator, and Therapy for Precision Medicine in Cancer. Clin. Transl Med. 8 (1), 24. doi:10.1186/s40169-019-0240-y

Cho, S. J., Moon, J. S., Lee, C. M., Choi, A. M., and Stout-Delgado, H. W. (2017). Glucose Transporter 1-Dependent Glycolysis Is Increased during AgingRelated Lung Fibrosis, and Phloretin Inhibits Lung Fibrosis. Am. J. Respir. Cell Mol Biol 56 (4), 521-531. doi:10.1165/rcmb.2016-0225OC

Cho, S. J., and Stout-Delgado, H. W. (2020). Aging and Lung Disease. Annu. Rev. Physiol. 82, 433-459. doi:10.1146/annurev-physiol-021119-034610

Cisneros, J., Hagood, J., Checa, M., Ortiz-Quintero, B., Negreros, M., Herrera, I., et al. (2012). Hypermethylation-mediated Silencing of p14(ARF) in Fibroblasts from Idiopathic Pulmonary Fibrosis. Am. J. Physiol. Lung Cell Mol Physiol 303 (4), L295-L303. doi:10.1152/ajplung.00332.2011
Coward, W. R., Saini, G., and Jenkins, G. (2010). The Pathogenesis of Idiopathic Pulmonary Fibrosis. Ther. Adv. Respir. Dis. 4 (6), 367-388. doi:10.1177/ 1753465810379801

Deng, Z., Fear, M. W., Suk Choi, Y., Wood, F. M., Allahham, A., Mutsaers, S. E., et al. (2020). The Extracellular Matrix and Mechanotransduction in Pulmonary Fibrosis. Int. J. Biochem. Cell Biol 126, 105802. doi:10.1016/ j.biocel.2020.105802

Desmoulière, A., Redard, M., Darby, I., and Gabbiani, G. (1995). Apoptosis Mediates the Decrease in Cellularity during the Transition between Granulation Tissue and Scar. Am. J. Pathol. 146 (1), 56-66.

Dobersch, S., Rubio, K., Singh, I., Günther, S., Graumann, J., Cordero, J., et al. (2021). Positioning of Nucleosomes Containing $\gamma-\mathrm{H} 2 \mathrm{AX}$ Precedes Active DNA Demethylation and Transcription Initiation. Nat. Commun. 12 (1), 1072. doi:10.1038/s41467-021-21227-y

Doubkova, M., Kriegova, E., Littnerova, S., Schneiderova, P., Sterclova, M., Bartos, V., et al. (2021). DSP Rs2076295 Variants Influence Nintedanib and Pirfenidone Outcomes in Idiopathic Pulmonary Fibrosis: a Pilot Study. Ther. Adv. Respir. Dis. 15, 17534666211042529. doi:10.1177/ 17534666211042529

Duerr, J., Leitz, D. H. W., Szczygiel, M., Dvornikov, D., Fraumann, S. G., Kreutz, C., et al. (2020). Conditional Deletion of Nedd4-2 in Lung Epithelial Cells Causes Progressive Pulmonary Fibrosis in Adult Mice. Nat. Commun. 11 (1), 2012. doi:10.1038/s41467-020-15743-6

Duncan, M. R., Frazier, K. S., Abramson, S., Williams, S., Klapper, H., Huang, X., et al. (1999). Connective Tissue Growth Factor Mediates Transforming Growth Factor Beta-Induced Collagen Synthesis: Down-Regulation by cAMP. FASEB J. 13 (13), 1774-1786. doi:10.1096/fasebj.13.13.1774

Duran-Ortiz, S., List, E. O., Basu, R., and Kopchick, J. J. (2021). Extending Lifespan by Modulating the Growth Hormone/insulin-like Growth Factor-1 axis: Coming of Age. Pituitary 24 (3), 438-456. doi:10.1007/s11102-020-01117-0

Elowsson Rendin, L., Löfdahl, A., Åhrman, E., Müller, C., Notermans, T., Michaliková, B., et al. (2019). Matrisome Properties of Scaffolds Direct Fibroblasts in Idiopathic Pulmonary Fibrosis. Int. J. Mol. Sci. 20 (16). doi:10.3390/ijms20164013

Espindola, M. S., Habiel, D. M., Coelho, A. L., Stripp, B., Parks, W. C., Oldham, J., et al. (2021). Differential Responses to Targeting Matrix Metalloproteinase 9 in Idiopathic Pulmonary Fibrosis. Am. J. Respir. Crit. Care Med. 203 (4), 458-470. doi:10.1164/rccm.201910-1977OC

Falke, L. L., He, N., Chuva de Sousa Lopes, S. M., Broekhuizen, R., Lyons, K., Nguyen, T. Q., et al. (2020). Correction to: FoxD1-Driven CCN2 Deletion Causes Axial Skeletal Deformities, Pulmonary Hypoplasia, and Neonatal Asphyctic Death. J. Cell Commun Signal 14 (1), 47-52. doi:10.1007/s12079020-00559-2

Fingerlin, T. E., Murphy, E., Zhang, W., Peljto, A. L., Brown, K. K., Steele, M. P., et al. (2013). Genome-wide Association Study Identifies Multiple Susceptibility Loci for Pulmonary Fibrosis. Nat. Genet. 45 (6), 613-620. doi:10.1038/ng.2609

Flaherty, K. R., Wells, A. U., Cottin, V., Devaraj, A., Walsh, S. L. F., Inoue, Y., et al. (2019). Nintedanib in Progressive Fibrosing Interstitial Lung Diseases. N. Engl. J. Med. 381 (18), 1718-1727. doi:10.1056/NEJMoa1908681

Frank, D. B., Peng, T., Zepp, J. A., Snitow, M., Vincent, T. L., Penkala, I. J., et al. (2016). Emergence of a Wave of Wnt Signaling that Regulates Lung Alveologenesis by Controlling Epithelial Self-Renewal and Differentiation. Cell Rep 17 (9), 2312-2325. doi:10.1016/j.celrep.2016.11.001

Gao, R., Peng, X., Perry, C., Sun, H., Ntokou, A., Ryu, C., et al. (2021). Macrophagederived Netrin-1 Drives Adrenergic Nerve-Associated Lung Fibrosis. J. Clin. Invest. 131 (1). doi:10.1172/JCI136542

Ghavami, S., Yeganeh, B., Zeki, A. A., Shojaei, S., Kenyon, N. J., Ott, S., et al. (2018). Autophagy and the Unfolded Protein Response Promote Profibrotic Effects of TGF-B1 in Human Lung Fibroblasts. Am. J. Physiol. Lung Cell Mol Physiol 314 (3), L493-L504. doi:10.1152/ajplung.00372.2017

Glass, D. S., Grossfeld, D., Renna, H. A., Agarwala, P., Spiegler, P., Kasselman, L. J., et al. (2020). Idiopathic Pulmonary Fibrosis: Molecular Mechanisms and Potential Treatment Approaches. Respir. Investig. 58 (5), 320-335. doi:10.1016/j.resinv.2020.04.002

Glassberg, M. K. (2019). Overview of Idiopathic Pulmonary Fibrosis, EvidenceBased Guidelines, and Recent Developments in the Treatment Landscape. Am. J. Manag. Care 25 (11 Suppl. 1), S195-S203. 
Gokey, J. J., Snowball, J., Sridharan, A., Speth, J. P., Black, K. E., Hariri, L. P., et al. (2018). MEG3 Is Increased in Idiopathic Pulmonary Fibrosis and Regulates Epithelial Cell Differentiation. JCI Insight 3 (17). doi:10.1172/jci.insight.122490

Grimminger, F., Günther, A., and Vancheri, C. (2015). The Role of Tyrosine Kinases in the Pathogenesis of Idiopathic Pulmonary Fibrosis. Eur. Respir. J. 45 (5), 1426-1433. doi:10.1183/09031936.00149614

Guiot, J., Henket, M., Corhay, J. L., Moermans, C., and Louis, R. (2017). Sputum Biomarkers in IPF: Evidence for Raised Gene Expression and Protein Level of IGFBP-2, IL-8 and MMP-7. PLoS One 12 (2), e0171344. doi:10.1371/ journal.pone.0171344

Hancock, L. A., Hennessy, C. E., Solomon, G. M., Dobrinskikh, E., Estrella, A., Hara, N., et al. (2018). Muc5b Overexpression Causes Mucociliary Dysfunction and Enhances Lung Fibrosis in Mice. Nat. Commun. 9 (1), 5363. doi:10.1038/ s41467-018-07768-9

Hao, Y., Bates, S., Mou, H., Yun, J. H., Pham, B., Liu, J., et al. (2020). Genome-Wide Association Study: Functional Variant Rs2076295 Regulates Desmoplakin Expression in Airway Epithelial Cells. Am. J. Respir. Crit. Care Med. 202 (9), 1225-1236. doi:10.1164/rccm.201910-1958OC

Herrera, J., Beisang, D. J., Peterson, M., Forster, C., Gilbertsen, A., Benyumov, A., et al. (2018). Dicer1 Deficiency in the Idiopathic Pulmonary Fibrosis Fibroblastic Focus Promotes Fibrosis by Suppressing MicroRNA Biogenesis. Am. J. Respir. Crit. Care Med. 198 (4), 486-496. doi:10.1164/rccm.201709$1823 \mathrm{OC}$

Hettiarachchi, S. U., Li, Y. H., Roy, J., Zhang, F., Puchulu-Campanella, E., Lindeman, S. D., et al. (2020). Targeted Inhibition of PI3 kinase/mTOR Specifically in Fibrotic Lung Fibroblasts Suppresses Pulmonary Fibrosis in Experimental Models. Sci. Transl Med. 12 (567). doi:10.1126/ scitranslmed.aay3724

Heukels, P., Moor, C. C., von der Thüsen, J. H., Wijsenbeek, M. S., and Kool, M. (2019). Inflammation and Immunity in IPF Pathogenesis and Treatment. Respir. Med. 147, 79-91. doi:10.1016/j.rmed.2018.12.015

Hewlett, J. C., Kropski, J. A., and Blackwell, T. S. (2018). Idiopathic Pulmonary Fibrosis: Epithelial-Mesenchymal Interactions and Emerging Therapeutic Targets. Matrix Biol. 71-72, 112-127. doi:10.1016/j.matbio.2018.03.021

Hipp, M. S., Kasturi, P., and Hartl, F. U. (2019). The Proteostasis Network and its Decline in Ageing. Nat. Rev. Mol. Cell Biol 20 (7), 421-435. doi:10.1038/s41580-0190101-y

Hohmann, M. S., Habiel, D. M., Coelho, A. L., Verri, W. A., Jr., and Hogaboam, C. M. (2019). Quercetin Enhances Ligand-Induced Apoptosis in Senescent Idiopathic Pulmonary Fibrosis Fibroblasts and Reduces Lung Fibrosis In Vivo. Am. J. Respir. Cell Mol Biol 60 (1), 28-40. doi:10.1165/rcmb.2017-0289OC

Hu, B., Gharaee-Kermani, M., Wu, Z., and Phan, S. H. (2010). Epigenetic Regulation of Myofibroblast Differentiation by DNA Methylation. Am. J. Pathol. 177 (1), 21-28. doi:10.2353/ajpath.2010.090999

Huan, C., Yang, T., Liang, J., Xie, T., Cheng, L., Liu, N., et al. (2015). Methylationmediated BMPER Expression in Fibroblast Activation in vitro and Lung Fibrosis in Mice in vivo. Sci. Rep. 5, 14910. doi:10.1038/srep14910

Huang, W. T., Akhter, H., Jiang, C., MacEwen, M., Ding, Q., Antony, V., et al. (2015). Plasminogen Activator Inhibitor 1, Fibroblast Apoptosis Resistance, and AgingRelated Susceptibility to Lung Fibrosis. Exp. Gerontol. 61, 62-75. doi:10.1016/ j.exger.2014.11.018

Huang, Y., Xie, Y., Abel, P. W., Wei, P., Plowman, J., Toews, M. L., et al. (2020). TGF- $\beta 1-$ induced miR-424 Promotes Pulmonary Myofibroblast Differentiation by Targeting Slit2 Protein Expression. Biochem. Pharmacol. 180, 114172. doi:10.1016/ j.bcp.2020.114172

Im, J., Hergert, P., and Nho, R. S. (2015). Reduced FoxO3a Expression Causes Low Autophagy in Idiopathic Pulmonary Fibrosis Fibroblasts on Collagen Matrices. Am. J. Physiol. Lung Cell Mol Physiol 309 (6), L552-L561. doi:10.1152/ ajplung.00079.2015

Inui, N., Sakai, S., and Kitagawa, M. (2021). Molecular Pathogenesis of Pulmonary Fibrosis, with Focus on Pathways Related to TGF- $\beta$ and the UbiquitinProteasome Pathway. Int. J. Mol. Sci. 22 (11). doi:10.3390/ijms22116107

Jenkins, R. G., Su, X., Su, G., Scotton, C. J., Camerer, E., Laurent, G. J., et al. (2006). Ligation of Protease-Activated Receptor 1 Enhances Alpha(v)beta6 Integrindependent TGF-Beta Activation and Promotes Acute Lung Injury. J. Clin. Invest. 116 (6), 1606-1614. doi:10.1172/JCI27183

John, A. E., Graves, R. H., Pun, K. T., Vitulli, G., Forty, E. J., Mercer, P. F., et al. (2020). Translational Pharmacology of an Inhaled Small Molecule av $\beta 6$ Integrin Inhibitor for Idiopathic Pulmonary Fibrosis. Nat. Commun. 11 (1), 4659. doi:10.1038/s41467020-18397-6

Jones, M. G., Andriotis, O. G., Roberts, J. J., Lunn, K., Tear, V. J., Cao, L., et al. (2018). Nanoscale Dysregulation of Collagen Structure-Function Disrupts Mechano-Homeostasis and Mediates Pulmonary Fibrosis. Elife 7. doi:10.7554/eLife.36354

Kadel, D., Zhang, Y., Sun, H. R., Zhao, Y., Dong, Q. Z., and Qin, L. X. (2019). Current Perspectives of Cancer-Associated Fibroblast in Therapeutic Resistance: Potential Mechanism and Future Strategy. Cell Biol Toxicol 35 (5), 407-421. doi:10.1007/s10565-019-09461-z

Kanaan, R., and Strange, C. (2017). Use of Multitarget Tyrosine Kinase Inhibitors to Attenuate Platelet-Derived Growth Factor Signalling in Lung Disease. Eur. Respir. Rev. 26 (146). doi:10.1183/16000617.0061-2017

Kang, J., and Song, J. W. (2021). Effect of Sildenafil Added to Antifibrotic Treatment in Idiopathic Pulmonary Fibrosis. Sci. Rep. 11 (1), 17824. doi:10.1038/s41598-021-97396-z

Kc, R., Shukla, S. D., Gautam, S. S., Hansbro, P. M., and O’Toole, R. F. (2018). The Role of Environmental Exposure to Non-cigarette Smoke in Lung Disease. Clin. Transl Med. 7 (1), 39. doi:10.1186/s40169-018-0217-2

Kishi, M., Aono, Y., Sato, S., Koyama, K., Azuma, M., Abe, S., et al. (2018). Blockade of Platelet-Derived Growth Factor Receptor- $\beta$, Not Receptor- $\alpha$ Ameliorates Bleomycin-Induced Pulmonary Fibrosis in Mice. PLoS One 13 (12), e0209786. doi:10.1371/journal.pone.0209786

Kropski, J. A., and Blackwell, T. S. (2018). Endoplasmic Reticulum Stress in the Pathogenesis of Fibrotic Disease. J. Clin. Invest. 128 (1), 64-73. doi:10.1172/ JCI93560

Kropski, J. A., Blackwell, T. S., and Loyd, J. E. (2015). The Genetic Basis of Idiopathic Pulmonary Fibrosis. Eur. Respir. J. 45 (6), 1717-1727. doi:10.1183/ 09031936.00163814

Kumar, A., Kapnadak, S. G., Girgis, R. E., and Raghu, G. (2018). Lung Transplantation in Idiopathic Pulmonary Fibrosis. Expert Rev. Respir. Med. 12 (5), 375-385. doi:10.1080/17476348.2018.1462704

Le Saux, C. J., and Chapman, H. A. (2018). Idiopathic Pulmonary Fibrosis: Cell Death and Inflammation Revisited. Am. J. Respir. Cell Mol Biol 59 (2), 137-138. doi:10.1165/rcmb.2018-0083ED

Leask, A. (2011). Possible Strategies for Anti-fibrotic Drug Intervention in Scleroderma. J. Cell Commun Signal 5 (2), 125-129. doi:10.1007/s12079011-0122-6

Lee, J. H., Tammela, T., Hofree, M., Choi, J., Marjanovic, N. D., Han, S., et al. (2017). Anatomically and Functionally Distinct Lung Mesenchymal Populations Marked by Lgr5 and Lgr6. Cell 170 (6), 1149-e12. e1112. doi:10.1016/j.cell.2017.07.028

Lee, T. H., Yeh, C. F., Lee, Y. T., Shih, Y. C., Chen, Y. T., Hung, C. T., et al. (2020). Fibroblast-enriched Endoplasmic Reticulum Protein TXNDC5 Promotes Pulmonary Fibrosis by Augmenting TGF $\beta$ Signaling through TGFBR1 Stabilization. Nat. Commun. 11 (1), 4254. doi:10.1038/s41467-020-18047-x

Li, F. J., Surolia, R., Li, H., Wang, Z., Liu, G., Kulkarni, T., et al. (2021). Citrullinated Vimentin Mediates Development and Progression of Lung Fibrosis. Sci. Transl Med. 13 (585). doi:10.1126/scitranslmed.aba2927

Li, L., Ma, B. B. Y., Chan, A. T. C., Chan, F. K. L., Murray, P., and Tao, Q. (2018). Epstein-Barr Virus-Induced Epigenetic Pathogenesis of Viral-Associated Lymphoepithelioma-like Carcinomas and Natural Killer/T-Cell Lymphomas. Pathogens 7 (3). doi:10.3390/pathogens7030063

Ligresti, G., Caporarello, N., Meridew, J. A., Jones, D. L., Tan, Q., Choi, K. M., et al. (2019). CBX5/G9a/H3K9me-mediated Gene Repression Is Essential to Fibroblast Activation during Lung Fibrosis. JCI Insight 5. doi:10.1172/jci.insight.127111

Lin, C. H., Shih, C. H., Lin, Y. C., Yang, Y. L., and Chen, B. C. (2018). MEKK1, JNK, and SMAD3 Mediate CXCL12-Stimulated Connective Tissue Growth Factor Expression in Human Lung Fibroblasts. J. Biomed. Sci. 25 (1), 19. doi:10.1186/s12929-018-0421-9

Lin, Y., and Xu, Z. (2020). Fibroblast Senescence in Idiopathic Pulmonary Fibrosis. Front Cell Dev Biol 8, 593283. doi:10.3389/fcell.2020.593283

Lipinski, J. H., Moore, B. B., and O'Dwyer, D. N. (2020). The Evolving Role of the Lung Microbiome in Pulmonary Fibrosis. Am. J. Physiol. Lung Cell Mol Physiol 319 (4), L675-L682. doi:10.1152/ajplung.00258.2020

Liu B, B., Yi, J., Yang, X., Liu, L., Lou, X., Zhang, Z., et al. (2019). MDM2-mediated Degradation of WRN Promotes Cellular Senescence in a P53-independent Manner. Oncogene 38 (14), 2501-2515. doi:10.1038/s41388-018-0605-5 
Liu F, F., Bayliss, G., and Zhuang, S. (2019). Application of Nintedanib and Other Potential Anti-fibrotic Agents in Fibrotic Diseases. Clin. Sci. (Lond) 133 (12), 1309-1320. doi:10.1042/CS20190249

Liu, G., Friggeri, A., Yang, Y., Milosevic, J., Ding, Q., Thannickal, V. J., et al. (2010). miR-21 Mediates Fibrogenic Activation of Pulmonary Fibroblasts and Lung Fibrosis. J. Exp. Med. 207 (8), 1589-1597. doi:10.1084/jem.20100035

Liu, Y. M., Nepali, K., and Liou, J. P. (2017). Idiopathic Pulmonary Fibrosis: Current Status, Recent Progress, and Emerging Targets. J. Med. Chem. 60 (2), 527-553. doi:10.1021/acs.jmedchem.6b00935

López-Otín, C., Blasco, M. A., Partridge, L., Serrano, M., and Kroemer, G. (2013). The Hallmarks of Aging. Cell 153 (6), 1194-1217. doi:10.1016/j.cell.2013.05.039

Lorenzo-Salazar, J. M., Ma, S. F., Jou, J., Hou, P. C., Guillen-Guio, B., Allen, R. J., et al. (2019). Novel Idiopathic Pulmonary Fibrosis Susceptibility Variants Revealed by Deep Sequencing. ERJ Open Res. 5 (2). doi:10.1183/ 23120541.00071-2019

Luo, Q. K., Zhang, H., and Li, L. (2020). Research Advances on DNA Methylation in Idiopathic Pulmonary Fibrosis. Adv. Exp. Med. Biol. 1255, 73-81. doi:10.1007/978-981-15-4494-1_6

Maher, T. M., Bendstrup, E., Dron, L., Langley, J., Smith, G., Khalid, J. M., et al. (2021). Global Incidence and Prevalence of Idiopathic Pulmonary Fibrosis. Respir. Res. 22 (1), 197. doi:10.1186/s12931-021-01791-z

Maher, T. M., Costabel, U., Glassberg, M. K., Kondoh, Y., Ogura, T., Scholand, M. B., et al. (2021). Phase 2 Trial to Assess Lebrikizumab in Patients with Idiopathic Pulmonary Fibrosis. Eur. Respir. J. 57 (2), 1902442. doi:10.1183/ 13993003.02442-2019

Makino, S. (2021). Progressive Fibrosing Interstitial Lung Diseases: A New Concept and Indication of Nintedanib. Mod. Rheumatol. 31 (1), 13-19. doi:10.1080/14397595.2020.1826665

Martinez, F. J., Collard, H. R., Pardo, A., Raghu, G., Richeldi, L., Selman, M., et al. (2017). Idiopathic Pulmonary Fibrosis. Nat. Rev. Dis. Primers 3, 17074. doi:10.1038/nrdp.2017.74

Mascaux, C., Laes, J. F., Anthoine, G., Haller, A., Ninane, V., Burny, A., et al. (2009). Evolution of microRNA Expression during Human Bronchial Squamous Carcinogenesis. Eur. Respir. J. 33 (2), 352-359. doi:10.1183/09031936.00084108

Massagué, J. (2012). TGF $\beta$ Signalling in Context. Nat. Rev. Mol. Cell Biol 13 (10), 616-630. doi:10.1038/nrm3434

Mathai, S. K., Pedersen, B. S., Smith, K., Russell, P., Schwarz, M. I., Brown, K. K., et al. (2016). Desmoplakin Variants Are Associated with Idiopathic Pulmonary Fibrosis. Am. J. Respir. Crit. Care Med. 193 (10), 1151-1160. doi:10.1164/ rccm.201509-1863OC

Merkt, W., Bueno, M., Mora, A. L., and Lagares, D. (2020). Senotherapeutics: Targeting Senescence in Idiopathic Pulmonary Fibrosis. Semin. Cell Dev Biol 101, 104-110. doi:10.1016/j.semcdb.2019.12.008

Moimas, S., Salton, F., Kosmider, B., Ring, N., Volpe, M. C., Bahmed, K., et al. (2019). miR-200 Family Members Reduce Senescence and Restore Idiopathic Pulmonary Fibrosis Type II Alveolar Epithelial Cell Transdifferentiation. ERJ Open Res. 5 (4). doi:10.1183/23120541.00138-2019

Molina-Molina, M., Machahua-Huamani, C., Vicens-Zygmunt, V., Llatjós, R., Escobar, I., Sala-Llinas, E., et al. (2018). Anti-fibrotic Effects of Pirfenidone and Rapamycin in Primary IPF Fibroblasts and Human Alveolar Epithelial Cells. BMC Pulm. Med. 18 (1), 63. doi:10.1186/s12890-018-0626-4

Molyneaux, P. L., Cox, M. J., Willis-Owen, S. A., Mallia, P., Russell, K. E., Russell, A. M., et al. (2014). The Role of Bacteria in the Pathogenesis and Progression of Idiopathic Pulmonary Fibrosis. Am. J. Respir. Crit. Care Med. 190 (8), 906-913. doi:10.1164/rccm.201403-0541OC

Molyneaux, P. L., Willis-Owen, S. A. G., Cox, M. J., James, P., Cowman, S., Loebinger, M., et al. (2017). Host-Microbial Interactions in Idiopathic Pulmonary Fibrosis. Am. J. Respir. Crit. Care Med. 195 (12), 1640-1650. doi:10.1164/rccm.201607-1408OC

Moore, C., Blumhagen, R. Z., Yang, I. V., Walts, A., Powers, J., Walker, T., et al. (2019). Resequencing Study Confirms that Host Defense and Cell Senescence Gene Variants Contribute to the Risk of Idiopathic Pulmonary Fibrosis. Am. J. Respir. Crit. Care Med. 200 (2), 199-208. doi:10.1164/rccm.201810-1891OC

Mora, A. L., Rojas, M., Pardo, A., and Selman, M. (2017). Emerging Therapies for Idiopathic Pulmonary Fibrosis, a Progressive Age-Related Disease. Nat. Rev. Drug Discov. 16 (11), 755-772. doi:10.1038/nrd.2017.22510.1038/ nrd.2017.170
Morse, C., Tabib, T., Sembrat, J., Buschur, K. L., Bittar, H. T., Valenzi, E., et al. (2019). Proliferating SPP1/MERTK-Expressing Macrophages in Idiopathic Pulmonary Fibrosis. Eur. Respir. J. 54 (2). doi:10.1183/13993003.02441-2018

Mortimer, K. M., Bartels, D. B., Hartmann, N., Capapey, J., Yang, J., Gately, R., et al. (2020). Characterizing Health Outcomes in Idiopathic Pulmonary Fibrosis Using US Health Claims Data. Respiration 99 (2), 108-118. doi:10.1159/ 000504630

Mulugeta, S., Nureki, S., and Beers, M. F. (2015). Lost after Translation: Insights from Pulmonary Surfactant for Understanding the Role of Alveolar Epithelial Dysfunction and Cellular Quality Control in Fibrotic Lung Disease. Am. J. Physiol. Lung Cell Mol Physiol 309 (6), L507-L525. doi:10.1152/ ajplung.00139.2015

Nabhan, A. N., Brownfield, D. G., Harbury, P. B., Krasnow, M. A., and Desai, T. J. (2018). Single-cell Wnt Signaling Niches Maintain Stemness of Alveolar Type 2 Cells. Science 359 (6380), 1118-1123. doi:10.1126/science.aam6603

Nathan, S. D., Costabel, U., Albera, C., Behr, J., Wuyts, W. A., Kirchgaessler, K. U., et al. (2019). Pirfenidone in Patients with Idiopathic Pulmonary Fibrosis and More Advanced Lung Function Impairment. Respir. Med. 153, 44-51. doi:10.1016/j.rmed.2019.04.016

Nho, R. S., Hergert, P., Kahm, J., Jessurun, J., and Henke, C. (2011). Pathological Alteration of FoxO3a Activity Promotes Idiopathic Pulmonary Fibrosis Fibroblast Proliferation on Type I Collagen Matrix. Am. J. Pathol. 179 (5), 2420-2430. doi:10.1016/j.ajpath.2011.07.020

O'Dwyer, D. N., Ashley, S. L., Gurczynski, S. J., Xia, M., Wilke, C., Falkowski, N. R., et al. (2019). Lung Microbiota Contribute to Pulmonary Inflammation and Disease Progression in Pulmonary Fibrosis. Am. J. Respir. Crit. Care Med. 199 (9), 1127-1138. doi:10.1164/rccm.201809-1650OC

Ornatowski, W., Lu, Q., Yegambaram, M., Garcia, A. E., Zemskov, E. A., Maltepe, E., et al. (2020). Complex Interplay between Autophagy and Oxidative Stress in the Development of Pulmonary Disease. Redox Biol. 36, 101679. doi:10.1016/ j.redox.2020.101679

Pardo, A., and Selman, M. (2021). The Interplay of the Genetic Architecture, Aging, and Environmental Factors in the Pathogenesis of Idiopathic Pulmonary Fibrosis. Am. J. Respir. Cell Mol Biol 64, 163-172. doi:10.1165/rcmb.20200373PS

Parimon, T., Yao, C., Stripp, B. R., Noble, P. W., and Chen, P. (2020). Alveolar Epithelial Type II Cells as Drivers of Lung Fibrosis in Idiopathic Pulmonary Fibrosis. Int. J. Mol. Sci. 21 (7). doi:10.3390/ijms21072269

Phan, T. H. G., Paliogiannis, P., Nasrallah, G. K., Giordo, R., Eid, A. H., Fois, A. G., et al. (2021). Emerging Cellular and Molecular Determinants of Idiopathic Pulmonary Fibrosis. Cell Mol Life Sci 78 (5), 2031-2057. doi:10.1007/s00018020-03693-7

Piñeiro-Hermida, S., Autilio, C., Martínez, P., Bosch, F., Pérez-Gil, J., and Blasco, M. A. (2020). Telomerase Treatment Prevents Lung Profibrotic Pathologies Associated with Physiological Aging. J. Cell Biol 219 (10). doi:10.1083/ jcb. 202002120

Plataki, M., Cho, S. J., Harris, R. M., Huang, H. R., Yun, H. S., Schiffer, K. T., et al. (2019). Mitochondrial Dysfunction in Aged Macrophages and Lung during Primary Streptococcus Pneumoniae Infection Is Improved with Pirfenidone. Sci. Rep. 9 (1), 971. doi:10.1038/s41598-018-37438-1

Qu, J., Yang, S. Z., Zhu, Y., Guo, T., Thannickal, V. J., and Zhou, Y. (2021). Targeting Mechanosensitive MDM4 Promotes Lung Fibrosis Resolution in Aged Mice. J. Exp. Med. 218 (5). doi:10.1084/jem.20202033

Qu, J., Zhu, L., Zhou, Z., Chen, P., Liu, S., Locy, M. L., et al. (2018). Reversing Mechanoinductive DSP Expression by CRISPR/dCas9-mediated Epigenome Editing. Am. J. Respir. Crit. Care Med. 198 (5), 599-609. doi:10.1164/ rccm.201711-2242OC

Rabinovich, E. I., Kapetanaki, M. G., Steinfeld, I., Gibson, K. F., Pandit, K. V., Yu, G., et al. (2012). Global Methylation Patterns in Idiopathic Pulmonary Fibrosis. PLoS One 7 (4), e33770. doi:10.1371/journal.pone.0033770

Racanelli, A. C., Kikkers, S. A., Choi, A. M. K., and Cloonan, S. M. (2018). Autophagy and Inflammation in Chronic Respiratory Disease. Autophagy 14 (2), 221-232. doi:10.1080/15548627.2017.1389823

Raghu, G., Brown, K. K., Collard, H. R., Cottin, V., Gibson, K. F., Kaner, R. J., et al. (2017). Efficacy of Simtuzumab versus Placebo in Patients with Idiopathic Pulmonary Fibrosis: a Randomised, Double-Blind, Controlled, Phase 2 Trial. Lancet Respir. Med. 5 (1), 22-32. doi:10.1016/S2213-2600(16)30421-0 
Raghu, G., Martinez, F. J., Brown, K. K., Costabel, U., Cottin, V., Wells, A. U., et al. (2015). CC-chemokine Ligand 2 Inhibition in Idiopathic Pulmonary Fibrosis: a Phase 2 Trial of Carlumab. Eur. Respir. J. 46 (6), 1740-1750. doi:10.1183/ 13993003.01558-2014

Rao, L. Z., Wang, Y., Zhang, L., Wu, G., Zhang, L., Wang, F. X., et al. (2021). IL-24 Deficiency Protects Mice against Bleomycin-Induced Pulmonary Fibrosis by Repressing IL-4-induced M2 Program in Macrophages. Cell Death Differ 28 (4), 1270-1283. doi:10.1038/s41418-020-00650-6

Reyfman, P. A., Walter, J. M., Joshi, N., Anekalla, K. R., McQuattie-Pimentel, A. C., Chiu, S., et al. (2019). Single-Cell Transcriptomic Analysis of Human Lung Provides Insights into the Pathobiology of Pulmonary Fibrosis. Am. J. Respir. Crit. Care Med. 199 (12), 1517-1536. doi:10.1164/rccm.201712-2410OC

Richeldi, L., Collard, H. R., and Jones, M. G. (2017). Idiopathic Pulmonary Fibrosis. Lancet 389 (10082), 1941-1952. doi:10.1016/S0140-6736(17)30866-8

Richeldi, L., Fernández Pérez, E. R., Costabel, U., Albera, C., Lederer, D. J., Flaherty, K. R., et al. (2020). Pamrevlumab, an Anti-connective Tissue Growth Factor Therapy, for Idiopathic Pulmonary Fibrosis (PRAISE): a Phase 2, Randomised, Double-Blind, Placebo-Controlled Trial. Lancet Respir. Med. 8 (1), 25-33. doi:10.1016/S2213-2600(19)30262-0

Ruwanpura, S. M., Thomas, B. J., and Bardin, P. G. (2020). Pirfenidone: Molecular Mechanisms and Potential Clinical Applications in Lung Disease. Am. J. Respir. Cell Mol Biol 62, 413-422. doi:10.1165/rcmb.2019-0328TR

Sakamoto, S., Kataoka, K., Kondoh, Y., Kato, M., Okamoto, M., Mukae, H., et al. (2021). Pirfenidone Plus Inhaled N-Acetylcysteine for Idiopathic Pulmonary Fibrosis: a Randomised Trial. Eur. Respir. J. 57 (1). doi:10.1183/ 13993003.00348-2020

Sanders, Y. Y., Ambalavanan, N., Halloran, B., Zhang, X., Liu, H., Crossman, D. K., et al. (2012). Altered DNA Methylation Profile in Idiopathic Pulmonary Fibrosis. Am. J. Respir. Crit. Care Med. 186 (6), 525-535. doi:10.1164/ rccm.201201-0077OC

Schäfer, S. C., Funke-Chambour, M., and Berezowska, S. (2020). Idiopathic Pulmonary Fibrosis-Epidemiology, Causes, and Clinical Course. Pathologe 41 (1), 46-51. doi:10.1007/s00292-019-00747-x

Selman, M., Martinez, F. J., and Pardo, A. (2019). Why Does an Aging Smoker's Lung Develop Idiopathic Pulmonary Fibrosis and Not Chronic Obstructive Pulmonary Disease? Am. J. Respir. Crit. Care Med. 199 (3), 279-285. doi:10.1164/rccm.201806-1166PP

Selvarajah, B., Azuelos, I., Platé, M., Guillotin, D., Forty, E. J., Contento, G., et al. (2019). mTORC1 Amplifies the ATF4-dependent de novo Serine-glycine Pathway to Supply glycine during TGF-B1-Induced Collagen Biosynthesis. Sci. Signal. 12 (582). doi:10.1126/scisignal.aav3048

Senoo, S., Taniguchi, A., Itano, J., Oda, N., Morichika, D., Fujii, U., et al. (2021). Essential Role of IL-23 in the Development of Acute Exacerbation of Pulmonary Fibrosis. Am. J. Physiology-Lung Cell Mol. Physiol. 321, L925-L940. doi:10.1152/ajplung.00582.2020

Sides, M. D., Klingsberg, R. C., Shan, B., Gordon, K. A., Nguyen, H. T., Lin, Z., et al. (2011). The Epstein-Barr Virus Latent Membrane Protein 1 and Transforming Growth Factor-B $\beta 1$ Synergistically Induce Epithelial-Mmesenchymal Transition in Lung Epithelial Cells. Am. J. Respir. Cell Mol Biol 44 (6), 852-862. doi:10.1165/rcmb.2009-0232OC

Somogyi, V., Chaudhuri, N., Torrisi, S. E., Kahn, N., Müller, V., and Kreuter, M. (2019). The Therapy of Idiopathic Pulmonary Fibrosis: what Is Next? Eur. Respir. Rev. 28 (153). doi:10.1183/16000617.0021-2019

Song, D., Tang, L., Wang, L., Huang, J., Zeng, T., Fang, H., et al. (2020). Roles of TGF $\beta 1$ in the Expression of Phosphoinositide 3-kinase Isoform Genes and Sensitivity and Response of Lung Telocytes to PI3K Inhibitors. Cell Biol Toxicol 36 (1), 51-64. doi:10.1007/s10565-019-09487-3

Song, M., Peng, H., Guo, W., Luo, M., Duan, W., Chen, P., et al. (2019). Cigarette Smoke Extract Promotes Human Lung Myofibroblast Differentiation by the Induction of Endoplasmic Reticulum Stress. Respiration 98 (4), 347-356. doi:10.1159/000502099

Spagnolo, P., Tzouvelekis, A., and Bonella, F. (2018). The Management of Patients with Idiopathic Pulmonary Fibrosis. Front. Med. (Lausanne) 5, 148. doi:10.3389/fmed.2018.00148

Stewart, G. A., Hoyne, G. F., Ahmad, S. A., Jarman, E., Wallace, W. A., Harrison, D. J., et al. (2003). Expression of the Developmental Sonic Hedgehog (Shh) Signalling Pathway Is Up-Regulated in Chronic Lung Fibrosis and the Shh
Receptor Patched 1 Is Present in Circulating T Lymphocytes. J. Pathol. 199 (4), 488-495. doi:10.1002/path.1295

Sui, B., Hu, C., and Jin, Y. (2016). Mitochondrial Metabolic Failure in Telomere Attrition-Provoked Aging of Bone Marrow Mesenchymal Stem Cells. Biogerontology 17 (2), 267-279. doi:10.1007/s10522-015-9609-5

Sun, W., Jing, X., Yang, X., Huang, H., Luo, Q., Xia, S., et al. (2021). Regulation of the IGF1 Signaling Pathway Is Involved in Idiopathic Pulmonary Fibrosis Induced by Alveolar Epithelial Cell Senescence and Core Fucosylation. Aging (Albany NY) 13 (14), 18852-18869. doi:10.18632/aging.203335

Surolia, R., Li, F. J., Wang, Z., Li, H., Dsouza, K., Thomas, V., et al. (2019). Vimentin Intermediate Filament Assembly Regulates Fibroblast Invasion in Fibrogenic Lung Injury. JCI Insight 4 (7). doi:10.1172/jci.insight.123253

Takezaki, A., Tsukumo, S. I., Setoguchi, Y., Ledford, J. G., Goto, H., Hosomichi, K., et al. (2019). A Homozygous SFTPA1 Mutation Drives Necroptosis of Type II Alveolar Epithelial Cells in Patients with Idiopathic Pulmonary Fibrosis. J. Exp. Med. 216 (12), 2724-2735. doi:10.1084/jem.20182351

Tsukui, T., Sun, K. H., Wetter, J. B., Wilson-Kanamori, J. R., Hazelwood, L. A., Henderson, N. C., et al. (2020). Collagen-producing Lung Cell Atlas Identifies Multiple Subsets with Distinct Localization and Relevance to Fibrosis. Nat. Commun. 11 (1), 1920. doi:10.1038/s41467-020-15647-5

Vancheri, C., Kreuter, M., Richeldi, L., Ryerson, C. J., Valeyre, D., Grutters, J. C., et al. (2018). Nintedanib with Add-On Pirfenidone in Idiopathic Pulmonary Fibrosis. Results of the INJOURNEY Trial. Am. J. Respir. Crit. Care Med. 197 (3), 356-363. doi:10.1164/rccm.201706-1301OC

Wang, J., Li, X., Zhong, M., Wang, Y., Zou, L., Wang, M., et al. (2020). miR-301a Suppression within Fibroblasts Limits the Progression of Fibrosis through the TSC1/mTOR Pathway. Mol. Ther. Nucleic Acids 21, 217-228. doi:10.1016/ j.omtn.2020.05.027

Wang, L., Chen, R., Li, G., Wang, Z., Liu, J., Liang, Y., et al. (2020). FBW7 Mediates Senescence and Pulmonary Fibrosis through Telomere Uncapping. Cell Metab 32 (5), 860-e9. doi:10.1016/j.cmet.2020.10.004

Wang, X., Cui, H., and Wu, S. (2019). CTGF: A Potential Therapeutic Target for Bronchopulmonary Dysplasia. Eur. J. Pharmacol. 860, 172588. doi:10.1016/ j.ejphar.2019.172588

Wang, Y., Zhang, L., Wu, G.-R., Zhou, Q., Yue, H., Rao, L.-Z., et al. (2021). MBD2 Serves as a Viable Target against Pulmonary Fibrosis by Inhibiting Macrophage M2 Program. Sci. Adv. 7 (1). doi:10.1126/sciadv.abb6075

Wang, Z., Qu, S., Zhu, J., Chen, F., and Ma, L. (2020). Comprehensive Analysis of lncRNA-Associated Competing Endogenous RNA Network and Immune Infiltration in Idiopathic Pulmonary Fibrosis. J. Thorac. Dis. 12 (5), 1856-1865. doi:10.21037/jtd-19-2842

Wilson, A. M., Clark, A. B., Cahn, T., Chilvers, E. R., Fraser, W., Hammond, M., et al. (2020). Effect of Co-trimoxazole (Trimethoprim-Sulfamethoxazole) vs Placebo on Death, Lung Transplant, or Hospital Admission in Patients with Moderate and Severe Idiopathic Pulmonary Fibrosis: The EME-TIPAC Randomized Clinical Trial. JAMA 324 (22), 2282-2291. doi:10.1001/ jama.2020.22960

Wipff, P. J., Rifkin, D. B., Meister, J. J., and Hinz, B. (2007). Myofibroblast Contraction Activates Latent TGF-Betal from the Extracellular Matrix. J. Cell Biol 179 (6), 1311-1323. doi:10.1083/jcb.200704042

Wolters, P. J., Collard, H. R., and Jones, K. D. (2014). Pathogenesis of Idiopathic Pulmonary Fibrosis. Annu. Rev. Pathol. 9, 157-179. doi:10.1146/annurevpathol-012513-104706

Wu, H., Yu, Y., Huang, H., Hu, Y., Fu, S., Wang, Z., et al. (2020). Progressive Pulmonary Fibrosis Is Caused by Elevated Mechanical Tension on Alveolar Stem Cells. Cell 180 (1), 107-e17. e117. doi:10.1016/j.cell.2019.11.027

Xia, H., Diebold, D., Nho, R., Perlman, D., Kleidon, J., Kahm, J., et al. (2008). Pathological Integrin Signaling Enhances Proliferation of Primary Lung Fibroblasts from Patients with Idiopathic Pulmonary Fibrosis. J. Exp. Med. 205 (7), 1659-1672. doi:10.1084/jem.20080001

Xiao, X., Huang, C., Zhao, C., Gou, X., Senavirathna, L. K., Hinsdale, M., et al. (2015). Regulation of Myofibroblast Differentiation by miR-424 during Epithelial-To-Mesenchymal Transition. Arch. Biochem. Biophys. 566, 49-57. doi:10.1016/j.abb.2014.12.007

Yamada, M. (2020). The Roles of MicroRNAs and Extracellular Vesicles in the Pathogeneses of Idiopathic Pulmonary Fibrosis and Acute Respiratory Distress Syndrome. Tohoku J. Exp. Med. 251 (4), 313-326. doi:10.1620/tjem.251.313 
Yanagihara, T., Tsubouchi, K., Gholiof, M., Chong, S. G., Lipson, K. E., Zhou, Q., et al. (2021). Connective-Tissue Growth Factor (CTGF/CCN2) Contributes to TGF-B1-Induced Lung Fibrosis. Am. J. Respir. Cell Mol Biol. doi:10.1165/ rcmb.2020-0504OC

Yang, G., Yang, L., Wang, W., Wang, J., Wang, J., and Xu, Z. (2015). Discovery and Validation of Extracellular/circulating microRNAs during Idiopathic Pulmonary Fibrosis Disease Progression. Gene 562 (1), 138-144. doi:10.1016/j.gene.2015.02.065

Yang, I. V., Pedersen, B. S., Rabinovich, E., Hennessy, C. E., Davidson, E. J., Murphy, E., et al. (2014). Relationship of DNA Methylation and Gene Expression in Idiopathic Pulmonary Fibrosis. Am. J. Respir. Crit. Care Med. 190 (11), 1263-1272. doi:10.1164/rccm.201408-1452OC

Yang, I. V., and Schwartz, D. A. (2015). Epigenetics of Idiopathic Pulmonary Fibrosis. Transl Res. 165 (1), 48-60. doi:10.1016/j.trsl.2014.03.011

Yang, S., Cui, H., Xie, N., Icyuz, M., Banerjee, S., Antony, V. B., et al. (2013). miR145 Regulates Myofibroblast Differentiation and Lung Fibrosis. FASEB J. 27 (6), 2382-2391. doi:10.1096/fj.12-219493

Yao, C., Guan, X., Carraro, G., Parimon, T., Liu, X., Huang, G., et al. (2021). Senescence of Alveolar Type 2 Cells Drives Progressive Pulmonary Fibrosis. Am. J. Respir. Crit. Care Med. 203, 707-717. doi:10.1164/rccm.202004-1274OC

Yoshihara, T., Nanri, Y., Nunomura, S., Yamaguchi, Y., Feghali-Bostwick, C., Ajito, K., et al. (2020). Periostin Plays a Critical Role in the Cell Cycle in Lung Fibroblasts. Respir. Res. 21 (1), 38. doi:10.1186/s12931-020-1299-0

Zacharias, W. J., Frank, D. B., Zepp, J. A., Morley, M. P., Alkhaleel, F. A., Kong, J., et al. (2018). Regeneration of the Lung Alveolus by an Evolutionarily Conserved Epithelial Progenitor. Nature 555 (7695), 251-255. doi:10.1038/nature25786

Zepp, J. A., Zacharias, W. J., Frank, D. B., Cavanaugh, C. A., Zhou, S., Morley, M. P., et al. (2017). Distinct Mesenchymal Lineages and Niches Promote Epithelial Self-Renewal and Myofibrogenesis in the Lung. Cell 170 (6), 1134-e10. doi:10.1016/j.cell.2017.07.034

Zhang, N., Liu, K., Wang, K., Zhou, C., Wang, H., Che, S., et al. (2019). Dust Induces Lung Fibrosis through Dysregulated DNA Methylation. Environ. Toxicol. 34 (6), 728-741. doi:10.1002/tox.22739

Zhang, Q., Wang, Y., Qu, D., Yu, J., and Yang, J. (2019). The Possible Pathogenesis of Idiopathic Pulmonary Fibrosis Considering MUC5B. Biomed. Res. Int. 2019, 9712464. doi:10.1155/2019/9712464
Zhang, Y., Jones, K. D., Achtar-Zadeh, N., Green, G., Kukreja, J., Xu, B., et al. (2019). Histopathological and Molecular Analysis of Idiopathic Pulmonary Fibrosis Lungs from Patients Treated with Pirfenidone or Nintedanib. Histopathology 74 (2), 341-349. doi:10.1111/his.13745

Zhao, Y. D., Yin, L., Archer, S., Lu, C., Zhao, G., Yao, Y., et al. (2017). Metabolic Heterogeneity of Idiopathic Pulmonary Fibrosis: a Metabolomic Study. BMJ Open Respir. Res. 4 (1), e000183. doi:10.1136/bmjresp-2017-000183

Zhou, Y., Huang, X., Hecker, L., Kurundkar, D., Kurundkar, A., Liu, H., et al. (2013). Inhibition of Mechanosensitive Signaling in Myofibroblasts Ameliorates Experimental Pulmonary Fibrosis. J. Clin. Invest. 123 (3), 1096-1108. doi:10.1172/JCI66700

Zhou, Z., Qu, J., He, L., Zhu, Y., Yang, S. Z., Zhang, F., et al. (2020). Stiff Matrix Instigates Type I Collagen Biogenesis by Mammalian Cleavage Factor I Complex-Mediated Alternative Polyadenylation. JCI insight 5 (3). doi:10.1172/jci.insight.133972

Zolak, J. S., and de Andrade, J. A. (2012). Idiopathic Pulmonary Fibrosis. Immunol. Allergy Clin. North. Am. 32 (4), 473-485. doi:10.1016/ j.iac.2012.08.006

Conflict of Interest: The authors declare that the research was conducted in the absence of any commercial or financial relationships that could be construed as a potential conflict of interest.

Publisher's Note: All claims expressed in this article are solely those of the authors and do not necessarily represent those of their affiliated organizations, or those of the publisher, the editors, and the reviewers. Any product that may be evaluated in this article, or claim that may be made by its manufacturer, is not guaranteed or endorsed by the publisher.

Copyright (C) $2022 \mathrm{Mei}$, Liu, Zuo, Yang and Qu. This is an open-access article distributed under the terms of the Creative Commons Attribution License (CC BY). The use, distribution or reproduction in other forums is permitted, provided the original author(s) and the copyright owner(s) are credited and that the original publication in this journal is cited, in accordance with accepted academic practice. No use, distribution or reproduction is permitted which does not comply with these terms. 